\author{
Universidade de São Paulo \\ Instituto de Química de São Carlos \\ Programa de Pós-Graduação em Química Analítica
}

\begin{abstract}
DESENVOLVIMENTO E CARACTERIZAÇÃO DE SENSORES ELETROQUÍMICOS BASEADOS EM NANOTUBOS DE CARBONO ALINHADOS COM DNA PARA A DETECÇÃO DE BISFENOL A
\end{abstract}

Aluno: Tiago Augusto da Silva 


\section{DESENVOLVIMENTO E CARACTERIZAÇÃO DE SENSORES ELETROQUÍMICOS BASEADOS EM NANOTUBOS DE CARBONO ALINHADOS COM DNA PARA A DETECÇÃO DE BISFENOL A}

Dissertação apresentada no Instituto de Química de São Carlos, da Universidade de São Paulo, como requisito obtenção do titulo de mestre.

Aluno: Tiago Augusto da Silva

Orientador: Prof. Dr. Sergio Antonio Spinola Machado

\section{Exemplar revisado}

O exemplar original encontra-se em

acervo reservado na Biblioteca do IQSC-USP

São Carlos 
Dissertação dedicada a DEUS, pela oportunidade de aprimorar meus conhecimentos;

Aos meus país Sônia e Neninho, por estarem ao meu lado me dando liberdade de escolha e confíando em mim em qualquer situação;

$\mathcal{A}$ Marina, pelo apoío, carinho e presença em minha vida. 


\section{AGRADECIMENTOS}

Primeiramente agradeço a Deus pelas inúmeras iluminações concedidas nos momentos de dificuldade e nos momentos de alegria. E pelo direito de sonhar, o que me mantém vivo.

Aos meus pais, Neninho e Sônia, que, além de me concederem a vida, também mantiveram o desejo em seus corações que eu estudasse e me desenvolvesse, mas que para isso fosse possível fizeram várias noites de hora extra na metalúrgica e várias horas em casa fazendo bolos e salgados. Vocês possuem a essência de serem Pai e Mãe, fazendo esquecer de vocês para dar a vida por mim.

A Marina, que durante todo esse tempo vem dedicando a mim tempo, carinho, paciência, estimulo, confiança, amizade, companheirismo. Obrigado pela sua dedicação e sua presença na minha vida.

Agradeço ao meu orientador, Prof. Dr. Sergio Antonio Spinola Machado, pela orientação e confiança dedicados durante dois anos. Espero alcançar o desenvolvimento necessário para retribuir sua atuação. E ao pós doutorando Fernando Cruz de Moraes o qual dedicou tempo e muito apoio no decorrer do mestrado.

Ao meu tio Sergio e a meu sogro Ronaldo. Por sempre estarem ao meu lado, preocupando-se com meus passos, proporcionando as melhores conversas e desejando que eu consiga realizar meus objetivos.

Aos amigos de Matão, Renan, Caio, Lucas, Ana, Luiz Eduardo, Michael, Artur e minha irmã Danieli os quais são exemplos de vida, e compartilham da minha vida a todo instante.

Aos amigos do GMEME, Dyovani, Livinha, Fernando, Yvana, Tony, Codorna, Paulo, Marcelo, João, Vanessa, Claudia, Vivian e Diego os quais me motivaram e foram presentes durante o mestrado.

À república Voadores, em especial Luiz, Luiz Henrique, Ricardo, Leandro, Diego, Madjer, Albiere e Isaac os quais proporcionaram momentos inesquecíveis e presenciaram meu dia-adia nesta cidade. 
"Jamais se contente com o pouco na sua vida, poís qualquer dia, ao invés de desejar sonhos, desejará pesadelos" (Autor desconhecido).

"O insucesso é a apenas uma oportunidade para recomeçar com mais intelígência." Henry Ford.

"Tudo que um sonho precisa para ser realizado é alguém que acredite que ele possa ser realizado." Roberto Shinyashiki

"A amizade é uma predisposição recíproca que torna dois seres igualmente cíosos da felicidade um do outro." Platão

..."Noão desista de nunca desistir"...

(Rosa de saron - Acenda a Luz) 


\section{Resumo}

Neste trabalho foram imobilizados nanotubos de carbono de parede simples sobre um eletrodo de ouro policristalino gerando uma camada de nanotubos alinhados verticalmente na superfície do eletrodo. Para isto, foi utilizado um fragmento de DNA (ssDNA tiol-terminado (5-HS-TGG-GGT-TTA-TGG-AAA-TTGGAA-3)) que foi posicionado ao redor do nanotubo de carbono com o procedimento seguinte: 1,0 mg SWCNT funcionalizado foi misturado com $1,0 \mathrm{~mL}$ de uma solução de ssDNA de $1,0 \mu \mathrm{mol} \mathrm{L}{ }^{-1}$, e o ssDNA foi preparado em $0,1 \mathrm{molL}^{-1}$ de PBS contendo cloreto de sódio a 10\% (v / v). Em seguida, a mistura foi sonicada usando uma sonda de ultrasom por $45 \mathrm{~min}$ e depois centrifugada a $10000 \mathrm{rpm}$ por $30 \mathrm{~min}$. Finalmente, um eletrodo de Au previamente limpo foi imerso na solução de sobrenadante e monocamadas auto-organizadas (SAM), que consistem de ssDNA/SWCNT foram formadas durante $24 \mathrm{~h}$ numa sala refrigerada a $4{ }^{\circ} \mathrm{C}$. As características morfológicas dos eletrodos foram determinadas por microscopia de força atômica, observando-se o alinhamento vertical, que alterou a rugosidade do eletrodo de 1,95 nm para 47,5 nm, com a altura média dos SWCNTs de 260,3 nm, com um desvio padrão relativo de $19,9 \%$. O comportamento eletroquímico do eletrodo de ouro modificado com o hibrido ssDNA/SWCNT foi caracterizado utilizando voltametria cíclica em meio de $\mathrm{Na}_{2} \mathrm{SO}_{4} 0,1 \mathrm{~mol}^{-1}$ contendo $\mathrm{K}_{3} \mathrm{Fe}(\mathrm{CN})_{6} 5,0 \mathrm{mmol} \mathrm{L}^{-1}$, com velocidade de varredura de potencial de $50 \mathrm{mVs}^{-1}$. Observou-se que a reversibilidade do par redox $\mathrm{Fe}(\mathrm{CN})_{6}{ }^{3-} / \mathrm{Fe}(\mathrm{CN})_{6}{ }^{4-}$ é maior para o eletrodo modificado com ssDNA/SWCNT $\left(\Delta \mathrm{E}_{\text {pico }}=80 \mathrm{mV}\right)$ quando comparado ao eletrodo de $\mathrm{Au}\left(\Delta \mathrm{E}_{\text {pico }}=115 \mathrm{mV}\right)$. A modificação proporcionou uma resposta mais eletrocatalítica com um deslocamento de $43 \mathrm{mV}$ para valores menos positivos do potencial de oxidação do $\mathrm{Fe}(\mathrm{CN})_{6}{ }^{3-}$. A oxidação no eletrodo de Au/ssDNA/SWCNTs ocorre em +417 mV e no eletrodo de $\mathrm{Au}$ em $+460 \mathrm{mV}$. Este aumento de reversibilidade foi quantificado por espectroscopia eletroquímica de impedância faradaica, onde se encontrou os valores de constantes de velocidade de $7.56 \times 10^{-5} \mathrm{~cm} \mathrm{~s}^{-1}$ para o eletrodo modificado e apenas $3,36 \times 10^{-5} \mathrm{~cm} \mathrm{~s}^{-1}$ para o de ouro puro. O efeito da modificação da superfície Au com o nanohíbrido ssDNA / SWCNT na oxidação do bisfenol-A (BPA) foi avaliado em $\mathrm{Na}_{2} \mathrm{SO}_{4} 0,1 \mathrm{~mol} \mathrm{~L}{ }^{-1}, \mathrm{pH}^{2}$

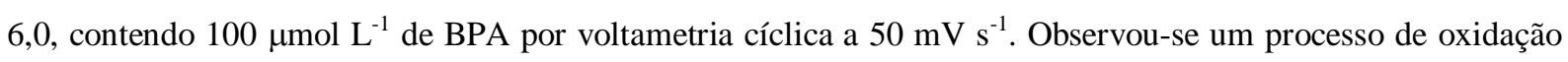
com um pico voltamétrico anódico num valor de potencial de $510 \mathrm{mV}$. Este processo de oxidação está relacionado com a eletro-oxidação de BPA para íons fenoxeno. O processo ocorreu em um potencial menos positivo do que o valor observado para o eletrodo de Au não modificado, ou seja $720 \mathrm{mV}$. Além disso, o processo oxidativo referente à superfície modificada mostrou-se mais catalítico, proporcionando um aumento do pico de oxidação de $163 \%$.

Para a metodologia analítica, procurou-se se maximizar o sinal analítico da técnica de voltametria de pulso diferencial, DPV, assim a resposta para o eletrodo de Au/ssDNA/SWCNT foi estudada em relação ao pH, salto de potenciais e a amplitude de pulso. Os valores ótimos encontrados foram 6,0,2 mV e $50 \mathrm{mV}$, respectivamente. Nestas condições o eletrodo de Au/ssDNA/SWCNT foi aplicado para a determinação de BPA em uma solução de $\mathrm{Na}_{2} \mathrm{SO}_{4} 0,1 \mathrm{~mol} \mathrm{~L}{ }^{-1}$, pH 6,0. A resposta analítica tem um comportamento linear na faixa entre 1,0 - 4,5 $\mu \mathrm{mol}$ $\mathrm{L}^{-1}$, de acordo com a seguinte equação: $I(\mu \mathrm{A})=0.019(\mu \mathrm{A})+5.82\left(\mu \mathrm{A} / \mu \mathrm{molL}^{-1}\right)[\mathrm{BPA}]$, com um coeficiente de correlação de $0,996(\mathrm{n}=10)$ e um limite de detecção (LOD) de $11,0 \mathrm{nmol} \mathrm{L}{ }^{-1}\left(2,51 \mu \mathrm{g} \mathrm{L}^{-1}\right)$ determinado de acordo com as recomendações da IUPAC. O valor obtido é menor que aqueles disponíveis na literatura. 
Abstract

In the present work, single-walled carbon nanotubes (SWCNT) were immobilized over top a polycrystalline gold electrode. This immobilization assembled a layer of vertically aligned nanotubes on the electrode surface. For this purpose, it was used a DNA probe (ssDNA thiolated (HS-5-TGGTTA-TGG-GGT-AAA-TTGGAA-3)) that has been used to wrap the carbon nanotube as the following procedure: $1.0 \mathrm{mg}$ of functionalized SWCNT was mixed with $1.0 \mathrm{~mL}$ of $1.0 \mu \mathrm{mol} \mathrm{L}^{-1}$ of a ssDNA solution prepared in $0.1 \mathrm{~mol} \mathrm{~L}^{-1}$ of PBS containing $10 \%(\mathrm{v} / \mathrm{v})$ of sodium chloride. Next, the mixture was sonicated using an ultrasonic horn probe and then centrifuged at $10000 \mathrm{rpm}$; each process took 45 min. Finally, a previously cleaned Au electrode was immersed in the supernatant solution. Selfassembled monolayers (SAMs) consisting of ssDNA/SWCNT were formed after $24 \mathrm{~h}$ in a refrigerated room at $4{ }^{\circ} \mathrm{C}$. The morphological characteristics of the electrodes were determined using atomic force microscopy. It was observed that the vertical alignment increased the electrode surface roughness of $1.95 \mathrm{~nm}$ to $47.5 \mathrm{~nm}$. The average height of the SWCNT was calculated at $260.3 \mathrm{~nm}$, with a relative standard deviation of $19.9 \%$. The electrochemical behavior of gold electrode modified with the ssDNA/SWCNT hybrid was characterized using cyclic voltammetry (CV) in $0.1 \mathrm{~mol} \mathrm{~L}^{-1}$ of $\mathrm{Na}_{2} \mathrm{SO}_{4}$ containing $5.0 \mathrm{mmol} \mathrm{L} \mathrm{L}^{-1}$ of $\left[\mathrm{K}_{3} \mathrm{Fe}(\mathrm{CN})_{6}\right]$, with a scan rate of $50 \mathrm{mVs}^{-1}$. It was observed that the reversibility of the redox couple $\mathrm{Fe}(\mathrm{CN})_{6}{ }^{3-} / \mathrm{Fe}(\mathrm{CN})_{6}{ }^{4-}$ decreased using the electrode modified with ssDNA/SWCNT $\left(\Delta \mathrm{E}_{\text {peak }}=80 \mathrm{mV}\right)$, when compared with the $\mathrm{Au}$ electrode $\left(\Delta \mathrm{E}_{\text {peak }}=115 \mathrm{mV}\right)$. The modification provided an electrocatalytic response with a shift of $43 \mathrm{mV}$ to less positive values on the $\mathrm{Fe}(\mathrm{CN})_{6}{ }^{3-}$ oxidation potential value. The oxidation on the $\mathrm{Au} / \mathrm{ssDNA} / \mathrm{SWCNT}$ electrode occurs at $+417 \mathrm{mV}$ and the $\mathrm{Au}$ electrode at $+460 \mathrm{mV}$. This improvement on the reversibility was quantified using the electrochemical impedance spectroscopy, in which it was observed an apparent constant rate at $7.56 \times 10^{-5} \mathrm{~cm} \mathrm{~s}^{-1}$ for the modified electrode and $3.36 \times 10^{-5} \mathrm{~cm} \mathrm{~s}^{-1}$ for pure gold. The effect of the modification of the Au surface with the nanohybrid ssDNA/SWCNT on the bisphenol A (BPA) oxidation was evaluated $0.1 \mathrm{~mol} \mathrm{~L}^{-1}$ of $\mathrm{Na}_{2} \mathrm{SO}_{4}$ (pH 6.0) containing $100 \mu \mathrm{mol} \mathrm{L}^{-1}$ of BPA. The system was evaluated using CV at $50 \mathrm{mV} \mathrm{s}^{-1}$. The CV experiments showed an oxidation process with an anodic peak potential at $510 \mathrm{mV}$. This oxidation process is attributed to the electro-oxidation of the BPA forming the fenoxene ions. The process occurred at a less positive potential value when compared with the unmodified Au electrode, i.e. 720 $\mathrm{mV}$. Moreover, surface modified with the nanohybrid presented more catalytic providing an increase of $163 \%$ on the oxidation current peak. For the analytical methodology, the analytical signal was maximized. For this, the differential pulse voltammetry (DPV) parameters such as: pulse amplitude and step potential and $\mathrm{pH}$ were optimized. The optimum values found were $\mathrm{pH}$ at 6.0 , pulse amplitude at $50 \mathrm{mV}$ and step potential at $2 \mathrm{mV}$. In these conditions, the Au/ssDNA/SWCNT electrode was applied for the BPA determination in $0.1 \mathrm{~mol} \mathrm{~L}^{-1}$ of $\mathrm{Na}_{2} \mathrm{SO}_{4}$. The analytical response showed a linear

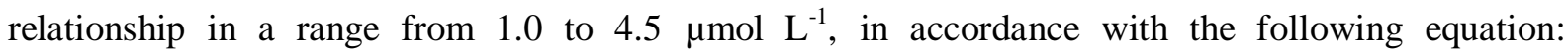
$\mathrm{I}(\mu \mathrm{A})=0.019(\mu \mathrm{A})+5.82\left(\mu \mathrm{A} / \mu \mathrm{mol} \mathrm{L}{ }^{-1}\right)[\mathrm{BPA}]$, with a correlation coefficient of $0.996(\mathrm{n}=10)$. The limit of detection (LOD) of $11.0 \mathrm{nmol} \mathrm{L}{ }^{-1}\left(2.51 \mu \mathrm{g} \mathrm{L}^{-1}\right)$ was determined in accordance with the IUPAC recommendations. The obtained value is smaller than those available in the literature. 
Lista de Figuras

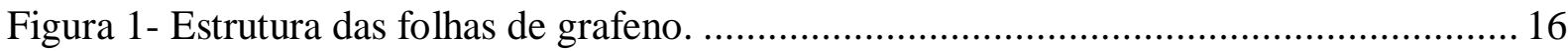

Figura 2 - Estrutura dos nanotubos de carbono de parede simples e paredes múltiplas. ........ 17

Figura 3- Esquema da funcionalização do nanotubo de carbono .......................................... 19

Figura 4 - Esquema de encapsulamento do CNT pelo ssDNA …........................................ 22

Figura 5 - Reação de formação de Bisfenol A...................................................................... 28

Figura 6 - Representação esquemática da célula eletroquímica utilizada durante os

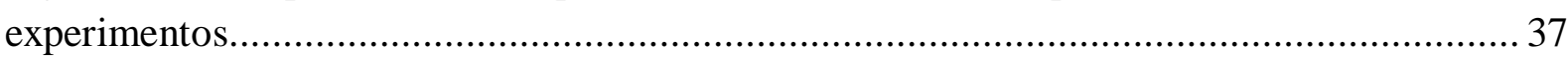

Figura 7- Imagens de AFM dos eletrodos: (A) Au sem modificação, (B) Au/ssDNA/SWCNT.

Detalhe: Gráficos de Topografia. ......................................................................... 42

Figura 8- Voltamogramas cíclicos de estado estacionário para os eletrodos de $\mathrm{Au}$ : (-) Au e (-) $\mathrm{Au} / \mathrm{DNA} / \mathrm{SWCNT}$ funcionalizados em $\mathrm{Na}_{2} \mathrm{SO}_{4} 0,1 \mathrm{~mol} \mathrm{~L}^{-1}$ contendo $\mathrm{Fe}(\mathrm{CN})_{6}{ }^{3-/ 4-}$ 5,0 mmol L ${ }^{-1}$ cada, a $50 \mathrm{mVs}^{-1}$............................................................................. 43

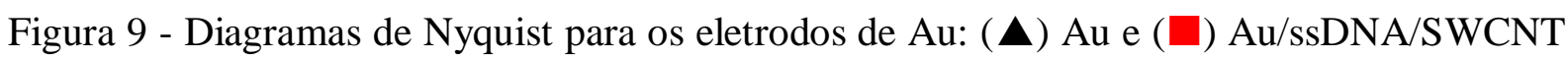
na presença de $\mathrm{Na}_{2} \mathrm{SO}_{4} 0,1 \mathrm{~mol} \mathrm{~L}^{-1}$ contendo $\mathrm{Fe}(\mathrm{CN})_{6}{ }^{3-14-} 1,0 \mathrm{mmol} \mathrm{L}^{-1}$. Os espectros foram coletados em potencial de circuito aberto, com frequência vaiando de $100 \mathrm{KHz}$ a $0,1 \mathrm{~Hz}$.... 44 Figura 10 - Voltamogramas de SWV em $0.1 \mathrm{~mol} \mathrm{~L}^{-1}$ de $\mathrm{NaOH}$ para: eletrodos $\mathrm{Au}$ sem modificação (linha vermelha) e o eletrodo modificado Au/ssDNA/SWCNT (linha preta).... 46 Figura 11 - Voltamogramas cíclicos de primeiro ciclo para O Bisfenol: eletrodo de $\mathrm{Au}($ - ) e de Au/DNA/SWCNT ( - ) funcionalizados, com 0,1 mol L-1 $\mathrm{Na}_{2} \mathrm{SO}_{4}$ contendo $100 \square \mathrm{mol} \mathrm{L}^{-1}$ de BPA, a $50 \mathrm{mVs}^{-1}$.

Figura 12 - Diagramas de Nyquist para o eletrodo de Au/ssDNA/SWCNT em: ( $\triangle$ ) $\mathrm{Na}_{2} \mathrm{SO}_{4}$ $0,1 \mathrm{~mol} \mathrm{~L}{ }^{-1},(\boldsymbol{\square}) \mathrm{Na}_{2} \mathrm{SO}_{4} 0,1 \mathrm{~mol} \mathrm{~L}^{-1}$ contendo BPA $0,1 \mathrm{mmol} \mathrm{L}{ }^{-1}$ e $(\bigcirc) \mathrm{Na}_{2} \mathrm{SO}_{4} 0,1 \mathrm{~mol} \mathrm{~L}^{-1}$ depois de 10 ciclos voltamétricos na solução de BPA

Figura 13 - Gráfico A representa a relação 3D entre o pH, a Epa e a Ipa. O gráfico B mostra a relação linear entre a variação de $\mathrm{pH}$ vs. $\mathrm{E}_{\mathrm{pa}}(\boldsymbol{\square})$ e $\mathrm{pH}$ vs. $\mathrm{I}_{\mathrm{pa}}(\boldsymbol{\square})$, em um meio $0,2 \mathrm{~mol} \mathrm{~L}^{-1}$ PBS contendo 1,0 mmol L ${ }^{-1}$ de BPA.

Figura 14 - Curva analítica utilizando DPV com o eletrodo de Au/ssDNA/SWCNT com os parâmetros otimizados para as seguintes concentrações de BPA em $\mu \mathrm{mol} \mathrm{L} \mathrm{L}^{-1}$ : (a) 1,00; (b) 1,50; (c) 2,00; (d) 2,50; (e) 3,00; (f) 3,50; (g) 4,00 e (h) 4,50. Detalhe: dependência linear do pico de corrente com a concentração de BPA.

\section{Lista de Tabelas}

Tabela 1- Sumário dos parâmetros de EIS estimados para os eletrodos, em $0,1 \mathrm{~mol} \mathrm{~L}^{-1}$ de $\mathrm{Na}_{2} \mathrm{SO}_{4}$ contendo 1,0 mmol L ${ }^{-1}$ de $\mathrm{K}_{3} \mathrm{Fe}(\mathrm{CN})_{6}$

Tabela 2. Otimizações dos parâmetros da técnica de DPV para a oxidação de BPA no eletrodo de Au/ssDNA/SWCNT 
Lista de Abreviações e Siglas

11 AUT 11-amino-1-undecanotiol

AB-DHP

Acetylene Black - dihexadecilhydrogênio phosfate

$\mathrm{HCl}$

Ácido clorídrico

$\mathrm{HNO}_{3}$

Ácido nítrico

ANVISA

Agência Nacional de Vigilância Sanitária

A

Amplitude do pulso

FIA

Análise por Injeção em fluxo

$\varphi$

Ângulo de helicidade

AFM

Atomic Force Microscopy

BPA

Bisfenol A

CNT

Carbon Nanotubes

CA

Cisteamina

$\mathrm{KCl}$

Cloreto de potássio

$\mathrm{Hg}_{2} \mathrm{Cl}_{2}$

Cloreto mercuroso

r

Coeficiente de correlação

CONAMA

Conselho Nacional do Meio Ambiente

kap

Constante aparente de velocidade

F

Constante de Faraday

$\mathrm{R}$

Constante física dos gases

Ipa

Correntes de pico anódicas

Ipc

Correntes de pico catódicas

GC-MS

Cromatografia em fase gasosa acoplada com espectrometria de massa

LC-ESI-MS

Cromatografia líquida com ionização por eletrospray acoplada a espectrometria de massa

Desvio padrão

$\mathrm{DE}$

Deteção eletroquímica

ECD

Deteção eletroquímica pelo método coulométrico

DES

dietilestilbestrol 
Enzima acetilcolinesterase

MS

Espectrometria de massa

EIE/EIS

Espectroscopia de Impedância Eletroquímica

XPS

Espectroscopia de raios $\mathrm{X}$ fotoelétrons

ETE

Estações de tratamento de esgoto

EMEA

European of Medicinal for the Evaluation Agency

$\alpha$

Expoente de heterogeneidade da superfície

MIP

Movie Impress Polipirrol

FL

Fluorescência

f

Frequência

$\mathrm{K}_{3}\left[\mathrm{Fe}(\mathrm{CN})_{6}\right]$

Hexacianoferrato de potássio

HPLC

High-Performance Liquid Chromatography

HPLC-ECD

HPLC com detecção eletroquímica pelo método coulométrico

HPLC-MS

HPLC com detecção por espectrometria de massa

$\mathrm{Z}_{\mathrm{w}}$

Impedância de Warburg

LOD

Limite de detecção

LOQ

Limite de quantificação

dsDNA

molécula de DNA de dupla fita

ssDNA

molécula de DNA de fita simples

MWCNT

Multi-Walled Carbon Nanotubes

$\mathrm{AgNO}_{3}$

Nitrato de prata

OCP

Open circuite potential

OECD

Organization for Economic Cooperation and Development

$\mathrm{Au}$

Ouro 


\begin{tabular}{|c|c|}
\hline $\mathrm{KMnO}_{4}$ & Permanganato de potássio \\
\hline PTFE & Politetrafluoretileno \\
\hline $\mathrm{E}_{\mathrm{L}}$ & Potencial de limpeza \\
\hline Epa & Potencial de pico anódico \\
\hline Epc & Potencial de pico catóditco \\
\hline $\mathrm{DE}$ & Potencial de varredura \\
\hline $\mathrm{R} \Omega$ & Resistência da célula \\
\hline Rs & Resistência da solução \\
\hline Rct & Resistência de transferência de carga \\
\hline qHNMR & Ressonância nuclear magnética quantitativa \\
\hline SAM & Self assemble monolayer \\
\hline SWCNT & Single-Walled Carbon Nanotubes \\
\hline PBS & Solução de Tampão Fosfato \\
\hline $\mathrm{Na}_{2} \mathrm{SO}_{4}$ & Sulfato de Sódio \\
\hline $\mathrm{T}$ & Temperatura \\
\hline $\mathrm{t}$ & Tempo de limpeza \\
\hline USEPA & U.S. Environmental Protection Agency \\
\hline UV & Ultravioleta \\
\hline $\mathrm{UE}$ & União Européia \\
\hline $\mathrm{Ch}$ & Vector Quiral \\
\hline $\mathrm{CV}$ & Voltametria ciclica \\
\hline VOQ & Voltametria de onda quadrada \\
\hline VPD & Voltametria de pulso diferencial \\
\hline
\end{tabular}




\section{Sumário}

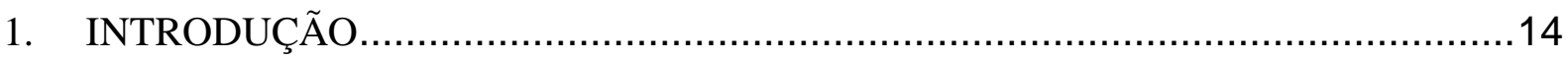

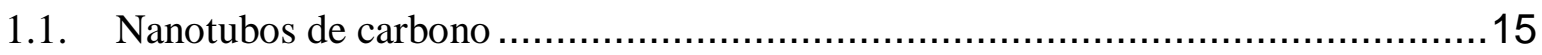

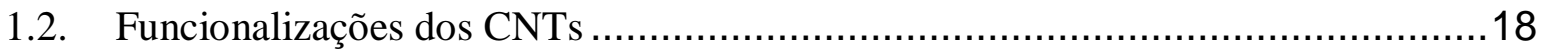

1.3. Monocamadas automontadas............................................................... 19

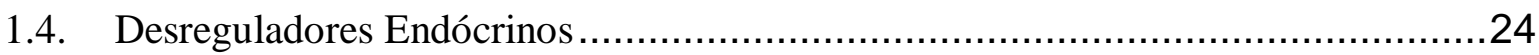

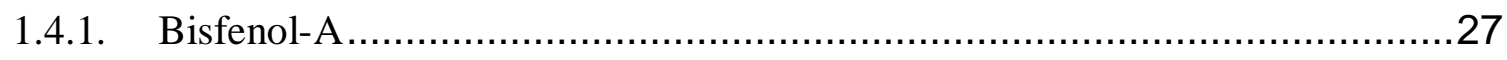

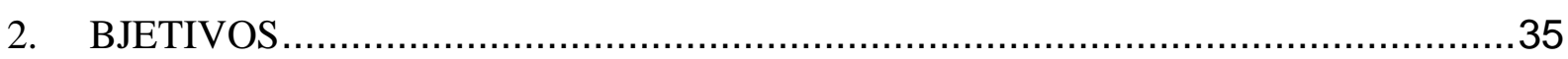

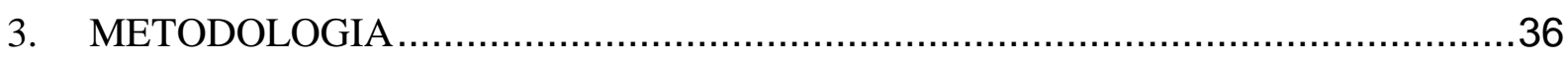

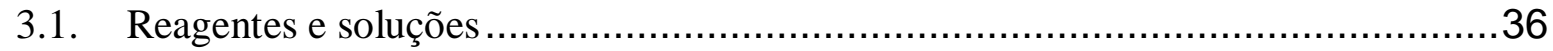

3.2. Materiais e instrumentos para medidas eletroquímicas ....................................36

3.2.1. Medidas Eletroquímicas ........................................................ 36

3.2.2. Medidas de Espectroscopia de Impedância Eletroquímica...........................36

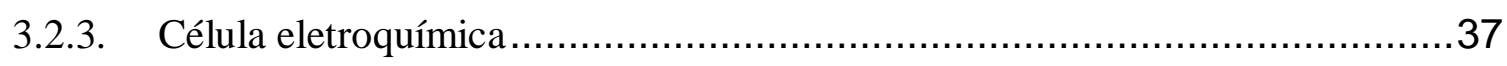

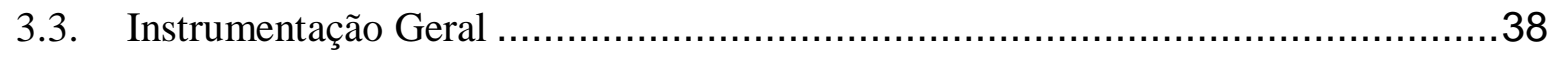

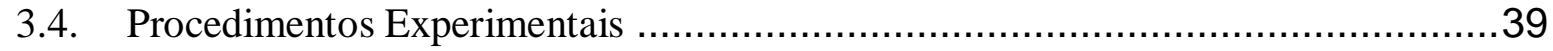

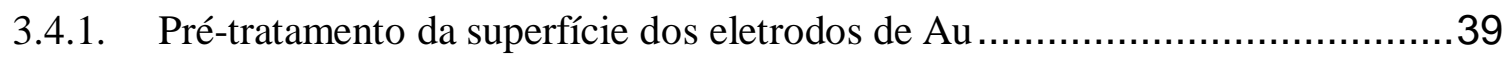

3.5. Procedimento para Modificação do eletrodo .......................................... 39

3.5.1. Modificação do eletrodo de trabalho ............................................ 39

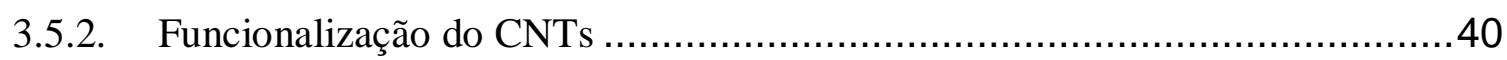

3.6. Caracterização morfológica e estrutural dos CNTs funcionalizados .....................40

3.7. Estudo do comportamento eletroquímico do Bisphenol-A ...............................40

3.7.1. Estudo do mecanismo redox do Bisphenol-A .................................. 40

3.7.2. Otimização dos parâmetros de análise para a construção da curva analítica do

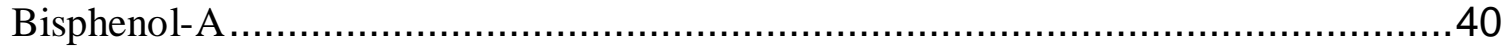

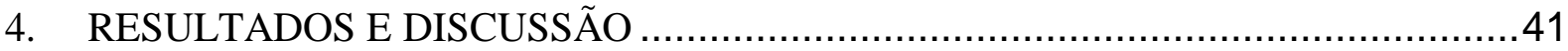

4.1. Caracterização da modificação da superfície do ouro com o nanohibrido

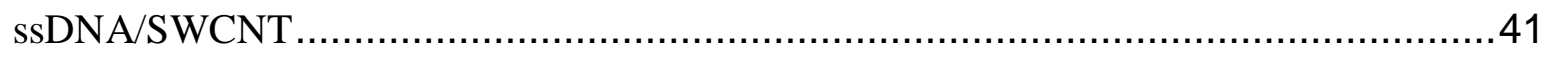

4.2 - Características eletroquímicas do Bisfenol-A ......................................... 47

4.2.1. Efeito da modificação do eletrodo com ssDNA / SWCNT na oxidação

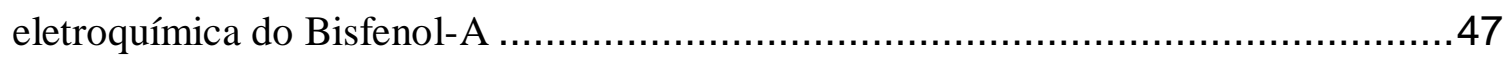

4.2.2. Estudos da adsorção do Bisfenol-A .............................................. 48

4.2.3. Estudos de otimização de Bisfenol-A no eletrodo Au/ssDNA/SWCNT ..............50

4.2.4. Características analíticas para o BPA …...............................................51 


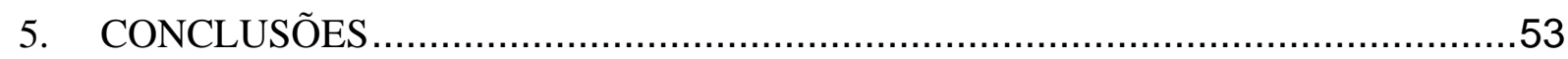

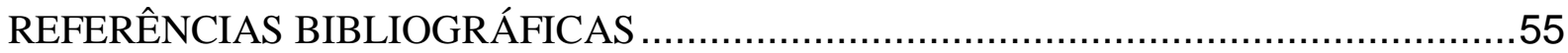




\section{INTRODUÇÃO}

A interferência do homem no meio ambiente - influenciado pelas necessidades de melhoria dos processos alimentícios, da pesquisa de novos compostos para a solução de problemas relacionados à saúde, de desenvolvimento da tecnologia e a busca crescente por conforto e bem estar - tem superado os limites estabelecidos pelos órgãos reguladores dos governos em relação à proteção do ecossistema, trazendo como resultado modificação e influências negativas sobre o próprio agente, o ser humano.

Como consequência tem-se produzido um número de compostos, naturais ou artificiais, cada vez maior e o destino final da grande parte desses compostos é o meio ambiente. A ação desses compostos sobre os organismos e ecossistemas tem gerado um número crescente de problemas, muitas vezes irreversíveis. A ação desses compostos sobre os organismos é tão determinante que sua aplicação é determinada por órgãos dos governos, com o objetivo de controlar e minimizar a potencialidade da ação sobre a vida.

No entanto nos deparamos com outro problema que é crucial no tratamento sobre os compostos presentes no meio ambiente, que é a falta de regulamentação para compostos recém-descobertos, não apresentando normalização para o uso, aplicação e descarte no ambiente.

Dentro desse quadro descrito podemos citar os interferentes endócrinos, os quais representam uma classe de compostos conhecida desse o inicio do século XX, e que promovem a alteração do funcionamento natural do sistema endócrino dos organismos expostos. Esse quadro tem despertado, ao longo dos anos, o interesse de vários setores da comunidade científica, apresentando um número significativo de trabalhos relatando as alterações causadas em animais e no ser humano.

Assim a necessidade de maior entendimento dos seus efeitos, a determinação precisa da ação desses compostos e, principalmente, a remediação de ambientes contaminados nos leva à busca pelo desenvolvimento de metodologias analíticas sensíveis e seletivas para o acompanhamento desses compostos de interesse no meio ambiente. Com o objetivo final de apresentar um método seguro e eficaz para o monitoramento de compostos que possibilite a tomada de decisão para os órgãos reguladores estabelecerem novas legislações controlando o descarte, o tratamento, evitando a bioacumulação e por fim reduzindo a ocorrência de danos à saúde dos organismos dependentes do meio ambiente contaminado. 


\subsection{Nanotubos de carbono}

Os nanotubos de carbono (CNT) cuja sigla deriva do inglês Carbon Nanotubes, desde a sua descoberta em $1991^{1}$, têm despertado muito interesse na comunidade científica para o desenvolvimento de materiais de alto desempenho ${ }^{2}$. Eles podem ser utilizados em diferentes áreas tecnológicas incluindo a aeroespacial, a automotiva, a de artigos esportivos e a de infraestrutura. Isto é devido à sua elevada durabilidade, alta resistência e baixa massa. Além disto, eles possuem capacidade de armazenamento de energia e são utilizados em dispositivos de conversão de energia, sensores, painéis de emissão de campo e fontes de radiação, como meios de armazenamento de hidrogênio e em dispositivos semicondutores de tamanho nanométrico, sondas, e interconexões ${ }^{3}$. Estas propriedades são devidas à combinação das propriedades mecânicas, elétricas e térmicas ao longo do eixo do tubo, o que fornece a possibilidade de controle sobre a química da superfície estudada, uma característica muito interessante na análise e recuperação de compostos de interesse ambiental, biológico ou medicinal, sem a introdução de impurezas metálicas ${ }^{4}$.

Pode-se melhorar substancialmente a condutividade, a força, a elasticidade, a resistência e a durabilidade dos compósitos, com a adição de CNT a esses materiais ${ }^{5}$, incluindo compósitos condutores e de alta resistência.

Outra definição importante sobre as características e propriedades físicas de um CNT é a maneira como a folha de grafeno é enrolada para formar o tubo cilíndrico ${ }^{3}$. A grandeza física que descreve este vetor, que é chamado vetor Quiral (Ch), ou vetor de Elicidade, e é indicado por um par de números inteiros $(\mathrm{n}, \mathrm{m})$ e pelos vetores unitários da rede hexagonal $(\mathrm{a} 1, \mathrm{a} 2)^{3}$, assim podemos escrever a equação por:

$$
\text { Ch }=\text { na1 }+ \text { ma2 } \quad \text { Equação } 1
$$

Os valores do par $(\mathrm{n}, \mathrm{m})$ determinam a geometria dos carbonos nos nanotubos, como podemos ver na Figura 1. Assim, temos que para a geometria do tipo "armchair" o par possui o valor de $n$ igual ao de m, Fig. 1B I, para a geometria tipo zig-zag os valores de n e m são iguais a zero, Fig. 1B II, e para a geometria quiral os valores de n são diferentes dos valores de m, que são diferentes de 0 e estão definidos pelo ângulo de helicidade $\varphi$, Fig. 1B III. 
Figura 1- Estrutura das folhas de grafeno.

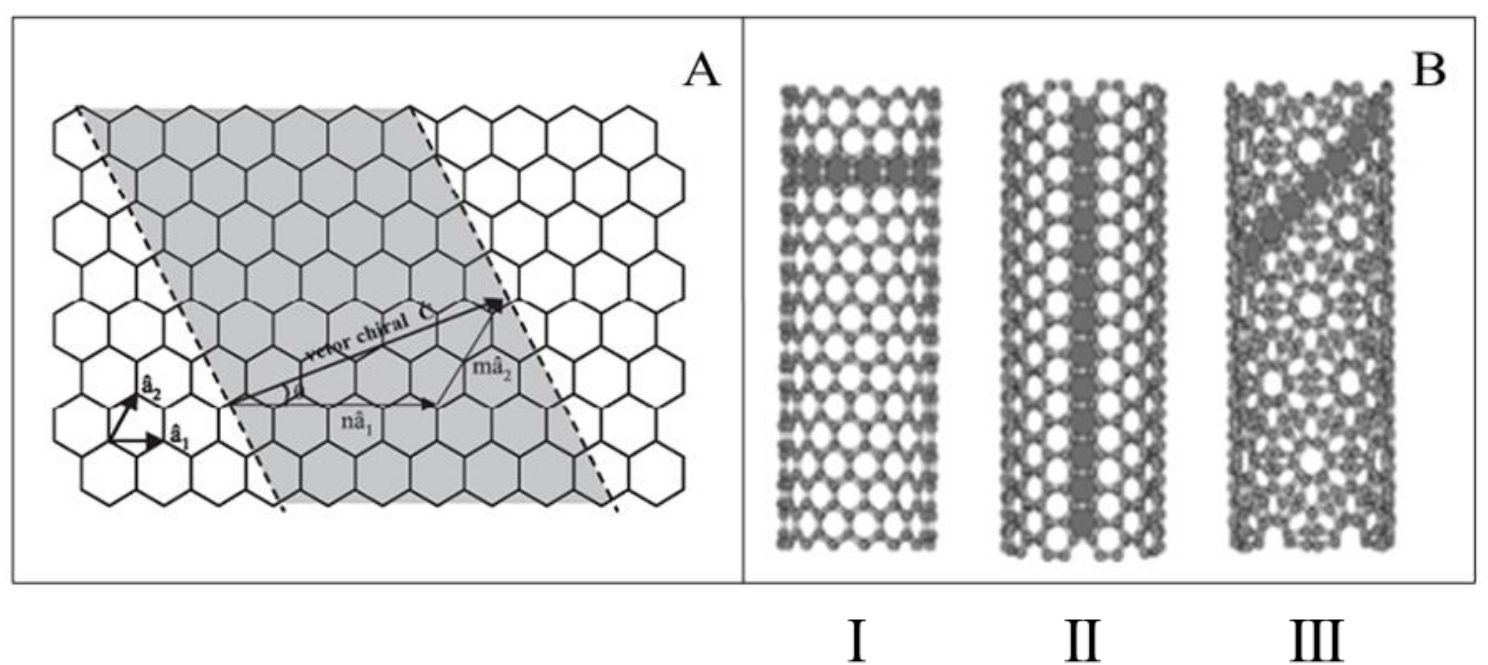

Se $\varphi$ varia de $0^{\circ}$ a $30^{\circ}$ podem ser gerados tubos partindo da geometria zig-zag e finalizando com armchair, passando pelos tubos quirais. O nanotubo é metálico quando o valor de n-m é múltiplo de 3; para qualquer valor diferente temos um caráter semicondutor. Assim os nanotubos do tipo armchair são metálicos, enquanto que os zig-zag e quiral podem se apresentar metálicos ou semicondutores ${ }^{6}$.

Do ponto de vista estrutural existem dois tipos de CNT: os nanotubos de carbono de parede simples (SWCNT) do inglês Single-Walled Carbon Nanotubes, que podem ser definidos como uma única folha de grafeno enrolada sobre si mesma para formar um tubo cilíndrico, e os nanotubos de carbono de parede múltipla (MWCNT), do inglês Multi-Walled Carbon Nanotubes, que representam um conjunto de três ou mais nanotubos concêntricos enrolados sobre si, como mostrados na Figura 2.

As propriedades eletrocatalíticas que os CNTs possuem, estão diretamente relacionadas ao tipo de transporte eletrônico que é possível realizar na parede dos tubos. Alguns estudos ${ }^{7-8}$ demonstraram que o transporte eletrônico nos CNTs pode ocorrer de forma balística, no plano basal, esse transporte somado a CNTs com comprimentos de nanotubos mais longos permite aos tubos transportar altas correntes sem essencialmente ocorrer aquecimento $^{3}$. 
Figura 2 - Estrutura dos nanotubos de carbono de parede simples e paredes múltiplas.
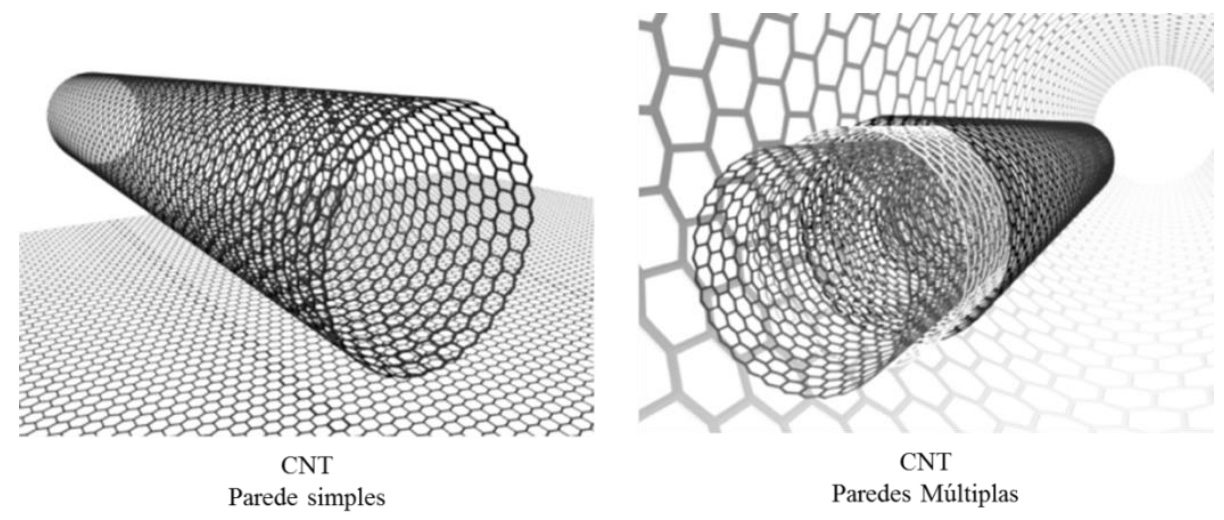

Antes da descoberta do nanotubo de carbono, o diamante era o melhor condutor térmico conhecido. Experimentos têm sido feitos sobre os CNT para determinação da sua condutividade térmica, a qual é pelo menos, duas vezes maior a do diamante à temperatura ambiente $^{3}$. Seu uso como material para o desenvolvimento de sensores tem adquirido importância fundamental, contudo a utilização de CNTs na área de eletroanálise é devido a duas de suas principais propriedades: a alta área superficial, que permite uma amplificação no sinal analítico e a segunda propriedade pronunciada, o poder eletrocatalítico conferido ao sistema.

Assim, os CNTs atendem às principais características de um material adequado para o desenvolvimento de sensores eletroquímicos, que podem ser descritas como: alta velocidade na transferência eletrônica, alta área superficial e a presença de grupos funcionais que fazem com que os sensores baseados em CNTs possam ser modificados com diversos tipos de moléculas ou íons, para diferentes aplicações. A formação desses grupos funcionais é realizada através da funcionalização química via tratamento em meio oxidante desse material, ocorrendo a oxidação dos átomos de carbono, produzindo grupos funcionais (carboxilas, hidroxilas, carbonilas, etc.) nas paredes dos CNTs. Estes grupos estão localizados principalmente nos planos de borda, estes planos de borda encontram-se principalmente em defeitos presentes no corpo do tubo além das extremidades. Tanto a condução balística quanto a presença de planos de borda fornecem a estes materiais a capacidade de mediar a transferência de elétrons em reações com espécies em solução 9 .

Devido às suas excelentes propriedades, os CNTs podem ser considerados candidatos atrativos como materiais em diferentes aplicações nanotecnologias e nanomédicas. No 
entanto, a falta de solubilidade e a difícil manipulação, em quaisquer solventes, impuseram grandes limitações a sua aplicação. Os CNTs podem ser dispersos em um limitado número de solventes através da utilização de ultra-sons, mas o material tende a se precipitar imediatamente quando o processo é interrompido. Isto demanda uma modificação dos CNTs com diferentes compostos como complexos supramoleculares, diferentes classes de compostos orgânicos, complexos metálicos, nanoestruturas, etc, possibilitando uma melhor manipulação sua aplicação ${ }^{3}$. No mesmo sentido a modificação química dos CNT é utilizada, pois os torna mais compatível para a sua integração em sistemas inorgânicos, orgânicos e biológicos.

\subsection{Funcionalizações dos CNTs}

A purificação e funcionalização dos CNTs são de fundamental importância para melhor manipulação do material. Os métodos de purificação têm como principal objetivo eliminar todos os resíduos de catalisadores utilizados para a síntese dos $\mathrm{CNTs}^{10}$. Este tratamento de purificação, que ocorre em meio oxidante, é facilmente encontrado na literatura, descrito por vários procedimentos diferentes ${ }^{10-12}$. A funcionalização ácida é o método mais utilizado para o tratamento desse material, dentre todos compostos utilizados a grande maioria dos trabalhos trazem a utilização do ácido nítrico concentrado $\left(\mathrm{HNO}_{3}\right)$ ou a mistura de ácido nítrico concentrado e ácido sulfúrico concentrado $\left(\mathrm{HNO}_{3} / \mathrm{H}_{2} \mathrm{SO}_{4}\right)$ na proporção de 3:1. A mistura de ácidos pode gerar maior densidade de grupos funcionais quando comparado ao tratamento com o $\mathrm{HNO}_{3}$ sozinho ${ }^{4}$.

Outro fator que pode influenciar na funcionalização dos CNTs é a temperatura, este fator pode aumentar a presença dos grupos funcionais, entretanto o tratamento em temperaturas muito elevadas pode comprometer a estrutura dos CNTs e diminuir o rendimento da sintese ${ }^{4}$. Estas alterações, causadas pelas modificações, são de fundamental importância, pois tornam os CNTs nanoestrurados e aumentam significativamente a população de planos de borda ${ }^{13}$, como apresentado na Figura 3.

$\mathrm{O}$ permanganato de potássio $\left(\mathrm{KMnO}_{4}\right)$ é um agente oxidante forte e, quando comparado ao tratamento com $\mathrm{HNO}_{3}$, é o método mais eficiente para introduzir os grupos funcionais nas bordas dos CNTs. Ainda comparando os meios oxidantes, existe a possibilidade de se utilizar o peróxido de hidrogênio, sua capacidade de oxidação é menor que 
a do $\mathrm{KMnO}_{4} \mathrm{e}$ das misturas ácidas, mas ao final do processo, não se encontra nenhum resíduo ácido ${ }^{4}$.

Figura 3- Esquema da funcionalização do nanotubo de carbono
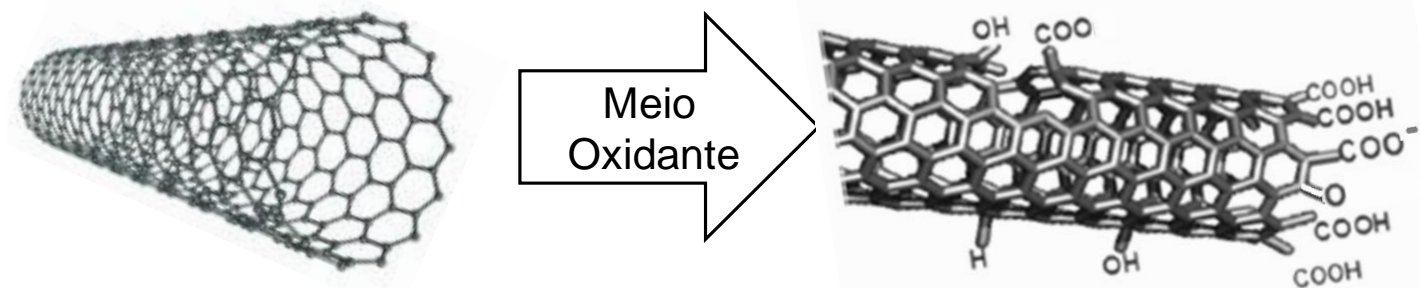

Outro efeito produzido no processo de purificação é que os CNTs são quebrados, tanto no comprimento quanto no diâmetro dos tubos ${ }^{13}$, consequentemente facilitando a introdução dos grupos de ácido carboxílico nas extremidades e nos locais de defeito nas paredes laterais dos nanotubos. Os grupos carboxílicos formados são fundamentais para as futuras modificações e transformações com grupos aminas, existentes em moléculas biológicas ${ }^{12}$.

A quebra dos CNTs no procedimento de purificação tem grande importância para a produção de biossensores eletroquímicos. Estudos demonstram que a quebra dos CNTs está ligada com o tempo de exposição ao ultra-som da amostra estudada. O comprimento dos CNTs diminui com o aumento do tempo de exposição, uma sonicação de 4 horas gera fragmentos de nanotubo de comprimento médio de $500 \mathrm{~nm}^{12}$.

Todas essas modificações direcionadas aos CNTs são muito úteis no desenvolvimento de sensores eletroquímicos ${ }^{14}$, uma vez que podem melhorar significativamente a integração com sistemas biológicos e com mediadores redox. É também uma proposta interessante para o ancoramento ou imobilização de drogas, enzimas, DNA e anticorpos tendo como principal objetivo elaborar um material em escala nanométrica visando aumentar a seletividade e a sensibilidade do sensor.

\subsection{Monocamadas automontadas}

Uma maneira de se fabricar sensores é utilizando as monocamadas automontadas (SAM - self assemble monolayer). Tais monocamadas proporcionaram condições de entender sistemas complexos como a permeabilidade química, transferência eletrônica e 
comportamento de microambientes em membranas celulares. A modificação de superfícies com esse método e as propriedades apresentadas por estes sistemas permitiram o desenvolvimento de sensores, biossensores, métodos de produção e estabilização de nanopartículas entre outros, que apresentavam-se inviáveis utilizando outros métodos ${ }^{15}$.

A formação dessas monocamadas está ligada à adsorção das moléculas por meio da quimissorção de tióis na superfície de ouro, o que confere uma maior estabilidade à monocamada formada, pois é formada uma ligação de caráter covalente entre o átomo de enxofre e o átomo de ouro ${ }^{15}$.

Com a adsorção das moléculas sobre a superfície do substrato concluída, a interação do tipo van der Waals entre as cadeias de hidrocarbonetos de moléculas vizinhas, dirigem a organização das moléculas formando a monocamada. Do ponto de vista termodinâmico, essa organização na superfície do substrato não é espontânea, uma vez que a entropia do sistema diminui, mas é possível observar a formação do sistema, pois a energia associada às interações laterais da cadeia carbônica sobrepõe à limitação entrópica. Assim, observamos que mesmo sendo espontâneo, o fenômeno de adsorção requer tempo ${ }^{15}$.

A modificação sobre a superfície utilizando SAMs em eletroanalítica tem grande aplicação, pois se o procedimento de montagem das monocamadas resultar em sistemas compactos e bem organizados, tais sistemas podem oferecer como vantagens o aumento de sensibilidade, seletividade, curto tempo de resposta e sobrepotencial reduzido em reações eletrocatalíticas. Muitos trabalhos têm relatado que a modificação da superfície de trabalho afeta diretamente a velocidade de transferência eletrônica entre as espécies eletroativas e o eletrodo ${ }^{15}$.

Com o objetivo de conseguir aliar as vantagens das SAMs e dispor todas as vantagens dos CNTs em um dispositivo eletroquímico de análise mediante as características citadas acima, muitos grupos de pesquisas vêm estudando possíveis modificações e materiais a serem utilizados em dispositivos para aliar ambos os materiais e assim obter um ganho de sensibilidade e reprodutibilidade para o sistema.

Uma das limitações na utilização dos CNTs está na sua interação de van der Waals entre os tubos, os CNTs aplicados sobre a superfície de um eletrodo tendem a se agregar rapidamente no processo de secagem, o que produz uma cobertura ineficiente reduzindo assim a reprodutibilidade entre os vários eletrodos modificados preparados. Embora esta limitação possa ser superada com a montagem de CNTs camada por camada, formando assim um filme 
espesso e compacto sobre o eletrodo, esse procedimento impede uma modificação adicional dos $\mathrm{CNTs}^{16}$.

Os procedimentos de modificação realizados nos CNTs podem ser divididos em duas classes: as modificações covalentes e as modificações não covalentes. Uma modificação covalente é reconhecida como sendo uma forma eficiente para a obtenção de dispersões de CNTs, uma vez que se reage um grupo químico que possui um caráter hidrofílico com o $\mathrm{CNTs}^{5}$. A funcionalização covalente é normalmente realizada a partir da reação dos aminogrupos presentes na molécula de DNA de fita simples (ssDNA) ou moléculas orgânicas, com os grupos carboxílicos dos CNTs previamente funcionalizados ${ }^{17}$.

A modificação não covalente ocorre com a utilização de moléculas com as paredes laterais dos CNTs, essas moléculas são fisicamente adsorvidas na superfície do CNT, e apresentam a vantagem de não alterarem a superfície CNT e podem facilitar a sua manipulação ${ }^{5}$.

Neste contexto, as moléculas de DNAs têm motivado pesquisadores a combinar esse material biológico com CNTs para explorar suas aplicações não biológicas ${ }^{18}$.

Em contraste com a abordagem tradicional, a qual moléculas de DNA são utilizados em ligação covalente com CNTs, verificou-se que DNA de fita simples (ssDNAs) de comprimentos diferentes, que são oligonucleótidos de cadeias pequenas compostas por dezenas de bases ou de sequências completamente aleatória de cadeias longas genômicas, podem enrolar em torno do SWCNTs para formar hélices apertadas. Simulações utilizando dinâmica molecular mostram que não há nenhuma evidência de formação desse mesmo sistema entre a cadeia de DNA de dupla fita (dsDNA) em torno de qualquer SWCNTs ${ }^{19}$.

Vários grupos relataram a funcionalização não covalente, por meio de acondicionamento de CNTs por ssDNA em soluções aquosas. O encapsulamento de SWCNTs por ssDNA ocorre quando as bases aromáticas dos nucleotídeos no ssDNA podem ser exposta para formar interações $\pi$ com a parede lateral hidrofóbica dos SWCNTs, enquanto que a parte hidrofílica do ssDNA (isto é, o açúcar-fosfato) é deixada exposta para interagir com o solvente. Eles também relataram que a interação entre ssDNA e o SWCNT converte os ssDNA em tubos individuais ${ }^{20}$, tem-se ao final do processo, um material de DNA enrolado em SWCNTs que pode ser utilizado para aplicações de dispositivos eletrônicos ou óptico, como podemos ver na Figura $4^{21}$.

A imobilização de cadeias de ssDNA em substratos sólidos, tais como ouro (Au), não é um processo simples, a reprodutibilidade é uma das principais preocupações na preparação 
de sensores de ssDNA utilizando a técnica de auto-montagem. Características como estabilidade, densidade e organização das SAMs dependem de vários fatores, tais como as forças de atração entre as moléculas imobilizadas, incluindo a interação entre os grupos terminais; forças entre a superfície e o grupo de ligação, e a estrutura do substrato sólido ${ }^{22-23}$.

Figura 4 - Esquema de encapsulamento do CNT pelo ssDNA

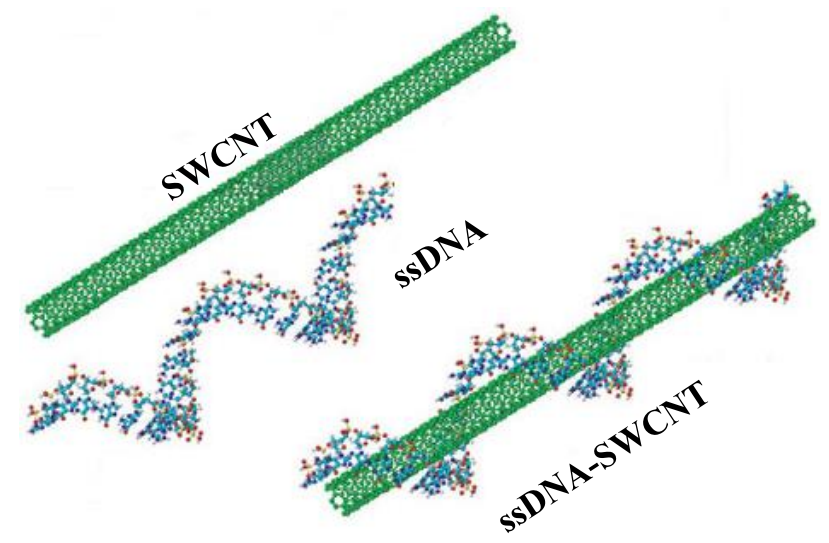

Este tipo de organização e alinhamento da superfície do eletrodo faz com que estes sistemas possuam alta sensibilidade e consequentemente sejam excelentes materiais para o desenvolvimento de sensores eletroquímicos. Um exemplo é o trabalho realizado por Viswanathan et $a l .{ }^{23}$, neste trabalho é descrito a construção e aplicação de um biossensor feito com a enzima acetilcolinesterase (AChE) para a detecção eletroquímica de inseticidas organofosforados. O eletrodo foi construído a partir do encapsulamento do SWCNT feito por fita de DNA (ssDNA) com terminação tiol. O sistema proposto foi disposto na forma de camada auto-organizada, sobre eletrodo de ouro e o alinhamento desta SAM foi constatado pela técnica de AFM (do inglês Atomic Force Microscopy). Sobre esta superfície foi depositado polianilina e a seguir foi imobilizada a enzima AChE. Os inseticidas foram determinados com limites de detecção na ordem de $10^{-12} \mathrm{~mol} \mathrm{~L}^{-1}$, mostrando a eficácia deste sistema.

Trabalhos recentes descrevem a formação de uma película de CNTs encapusulados em ssDNA sobre suportes sólidos para aplicação eletroquímica ${ }^{22,24}$. Um método interessante para o alinhamento nanotubos de carbono é a técnica de automontagem com a formação de $\mathrm{SAMs}^{25-26}$.

Zheng et al. (2003) ${ }^{27}$ mostraram em seu trabalho o acondicionamento de nanotubos de carbono (CNT) por ssDNA. Após a pesquisa de sequências de ssDNA selecionou se uma 
sequência que possui a característica de auto-organiza-se em uma estrutura helicoidal em torno de nanotubos individuais. Os estudos demonstraram que a eletrostática do híbrido DNA-CNT formado depende do diâmetro do tubo e as propriedades eletrônicas, permitindo a separação de nanotubos por cromatografia de permuta aniônica.

Dwyer et al. $(2002)^{28}$ descreveram uma a tentativa de imobilizar ssDNA com terminação amino em SWCNT funcionalizado. Esta forma de modificação química é o primeiro passo para a implementação de moléculas de DNA em processo de auto-montagem capaz de orientar a colocação de nanotubos de carbono este trabalho apresenta o início de um argumento convincente para a viabilidade de auto-montagem molecular em sistemas eletrônicos.

Kerman et al. (2004) ${ }^{29}$ usaram nanotubos de carbono de paredes múltiplas (MWNTs) como nanofios, combinados a moléculas de DNA, em um eletrodo de pasta de carbono (EPC). A fixação do MWCNT sobre o eletrodo foi controlado pela hibridização entre a adenina e a timina que contêm oligonucleotidos. A promissora condutividade dos MWCNT e a obtenção de uma área superficial maior com a imobilização de DNA proporcionou um limite de detecção de $10 \mathrm{pg} \mathrm{mL}^{-1}$.

Polames et al. $(2007)^{23}$ apresentaram um trabalho com a formação de uma SAM, utilizando um hibrido de ssDNA modificado com dissulfeto ancorado em substrato de ouro. Os resultados mostraram a formação de uma monocamada mais compacta de ssDNA/CNT quando comparado com DNA. A conclusão dos autores é que a utilização desse sistema pode representar uma nova metodologia de imobilização das cadeias de DNA em ouro, e auxiliar no desenvolvimento de sensores.

Guiseppi-Elie et al. $(2010)^{30}$ estudaram a construção de um transdutor, eletrodo de microdisco de ouro, modificado com CNT funcionalizados, covalentemente ligados a SAMs de alquano tiol, as SAMs formadas foram de cisteamina (CA) e 11-amino-1-undecanetiol (11AUT). Como esperado, a modificação de Au com CA produziu um filme desordenado que não modificou a área superficial efetiva. Enquanto o eletrodo de ouro modificado com 11AUT resultou na passivação e uma redução de $50 \%$ da área superficial efetiva. A conjugação do SWNT com o CA-modificado e o 11-AUT-modificado alterou a área superficial, trazendo uma aumento de área de $200 \%$ para o sistema Au/CA/SWCNT e uma aumento de $100 \%$ para o sistema Au/11-AUT/SWCNT. Os dados de AFM mostraram SWCNTs ficaram orientadas verticalmente na superfície do CA-modificado, mas para o disposto modificado com a 11AUT, o arranjo final foi horizontal e agrupado na superfície. 
Hu et al. $(2005)^{18}$ dispersaram SWCNTs e encapsularam com ssDNA, esse sistema foi anexado fortemente em um substrato de vidro formando assim uma película uniforme. $\mathrm{O}$ filme depositado em um eletrodo de trabalho apresentava excelentes propriedades eletroquímicas, como plana e larga janela de potencial, bem definidos quasi-reversíveis respostas voltamétricas e transferência de elétrons rápido para um $\mathrm{Fe}(\mathrm{CN})_{6}{ }^{-3} / \mathrm{Fe}(\mathrm{CN})_{6}^{-4}$ do sistema. O sistema foi aplicado para detecção de dopamina, apresentou-se altamente sensível e seletivo para uma baixa concentração do composto na presença de excesso de ácido ascórbico, com limite de detecção de $5.0 \times 10^{-8} \mathrm{M}$.

\subsection{Desreguladores Endócrinos}

O termo desreguladores endócrinos possui várias definições na literatura todas as quais estão relacionadas com a capacidade de interferência desses compostos ${ }^{31}$. Devido à sua presença no meio ambiente, tem crescido o interesse da sociedade científica com relação a determinação e a identificação da ação destes compostos sobre organismos e ecossistemas, resultando em vários trabalhos.

O sistema endócrino é o conjunto de glândulas localizadas em diferentes áreas do corpo, tais como a tireóide, as glândulas supra-renais e as gônadas. Também fazem parte desse sistema os hormônios produzidos nessas glândulas, os quais tem a capacidade de controlar as mais variadas funções essenciais para o desenvolvimento e manutenção do organismo como níveis de sais, açúcares, o controle das quantidades de líquidos no sangue, o uso e armazenamento de energia, o crescimento e o desenvolvimento de um determinado organismo, sua reprodução e suas características sexuais ${ }^{32}$. Mediante a importância da ação desses hormônios sobre o organismo, uma substância química desreguladora endócrina representa um perigo para os mais diversos destinos que esta alcançará ${ }^{33}$.

Muitas substâncias tem demonstrado potencial para serem classificadas como desreguladores endócrinos, por esse motivo várias definições são encontradas na literatura. Em maio de 1997, a agência de proteção ambiental dos Estados Unidos ("U.S. Environmental Protection Agency - USEPA”), por meio do seu comitê consultivo responsável pela avaliação e diagnóstico de interferentes endócrinos ("Endocrine Disrupter Screening and Testing Advisory Committee - EDSTAC”), propôs uma definição detalhada que considera também os mecanismos envolvidos nas disfunções do sistema endócrino. A agência descreve um "interferente endócrino" como sendo uma substância ou mistura química exógena que altera 
uma ou mais funções do sistema endócrino, bem como a sua estrutura, causando efeitos adversos tanto sobre um organismo e sua descendência, como em populações ou subpopulações de organismos, tendo como base estudos científicos, dados, evidências de peso e princípios de precaução",33-34.

Outra definição encontrada na literatura cita que interferente endócrino em potencial trata-se de "a substance that possesses properties that might be expected to lead to endocrine disruption in an intact organism (uma substância que possui propriedades que podem se esperada conduzam à desregulação endócrina de um organismo intacto)"34-36. Encontramos também segundo documento redigido pela União Européia (UE), “os desreguladores endócrinos podem: danificar diretamente um órgão endócrino; alterar diretamente a função de um órgão endócrino; interagir com um receptor de hormônios ou, alterar o metabolismo de um hormônio em um órgão endócrino"31.

O Programa Internacional de Segurança Química em trabalho conjunto com o Japão, os EUA, o Canadá, a OECD (Organisation for Economic Cooperation and Development) e a União Européia, adotou a seguinte definição: “Um desregulador endócrino é uma substância ou um composto exógeno que altera uma ou várias funções do sistema endócrino e, consequentemente, tem efeitos adversos sobre a saúde num organismo intacto, sua descendência, ou (sub) populações"31,37.

Desta maneira, temos muitas definições propostas para tratar de desreguladores endócrinos, mas todas possuem um ponto em comum, a qual descreve uma substância que tem o potencial de interferir no funcionamento natural do sistema endócrino de espécies animais, incluindo o ser humano ${ }^{32}$.

Podemos dividir os desreguladores endócrinos em duas classes: substâncias naturais e substâncias sintéticas. Os desreguladores endócrinos naturais incluem os hormônios presentes no corpo humano e fitoestrogênios, os quais são de origem vegetal. Esses compostos geralmente não trazem tantos riscos para os organismos, uma vez que não se ligam fortemente aos receptores hormonais sendo facilmente excretadas e não se acumulando nos tecidos corpóreos.

A segunda classe, de substâncias sintéticas, é composta por hormônios que são utilizados como contraceptivos, aditivos na alimentação animal, substâncias utilizadas na indústria, pesticidas entre outros. Tais substâncias apresentam como característica a capacidade de acumulação no ambiente, acumulando-se em solos e sedimentos. São transportadas facilmente para outras regiões pelos corpos d'água e podem se acumular ao 
longo da cadeia trófica, o que traz grande risco para os seres humanos que estão no topo da cadeia alimentar ${ }^{33}$.

Os primeiros indícios sobre a ação dos desreguladores endócrinos em organismos vivos são associados a vários acontecimentos na história, entre as datas de 1940 a 1972 onde foram notificados o aparecimento de câncer no sistema reprodutivo de filhas de mulheres que usaram DES (dietilestilbestrol) na gravidez; anomalias no sistema reprodutivo observadas em jacarés que habitavam um lago na Flórida contaminado com o pesticida DDT e seu metabólito DDE3, e um estudo na Dinamarca que relata o declínio da qualidade do sêmen de homens durante aproximadamente 50 anos, entre os anos de 1938 e $1990^{31}$.

A atual atenção dos pesquisadores está voltada para o entendimento da relação da exposição de humanos e outros animais a baixas concentrações dos desreguladores endócrinos, compreender quais substâncias estão relacionadas aos efeitos tóxicos em baixas concentrações; se esses compostos estão presentes em concentrações ambientalmente relevantes que possam ser um motivo de preocupação à saúde de humanos e animais, e ainda se existe uma concentração limite, a qual esses compostos podem ser considerados como substâncias seguras, uma vez que os interferentes endócrinos são encontrados no meio ambiente em concentração da ordem de $\mu \mathrm{g} \mathrm{L}^{-1}$ e $n g \mathrm{~L}^{-1} 31$.

No meio ambiente existem vários compostos com a capacidade de desregulação do sistema endócrino, podemos citar como substâncias sintéticas os alquilfenóis, pesticidas, ftalatos, policlorados de bifenilas, bisfenol A, substâncias farmacêuticas, entre outras, e as substâncias naturais como os estrogênios naturais e fitoestrogênios. Mediante à dificuldade de identificação desses micropoluentes no meio ambiente, muitos métodos analíticos foram desenvolvidos para detectar e quantificar essas substâncias em matrizes ambientais complexas, como águas superficiais e subterrâneas, esgoto doméstico, efluentes de estações de tratamento de esgoto (ETE), sedimentos marinhos, solo e lodo biológico. $\mathrm{Na}$ mesma direção faz-se necessidade sobre o conhecimento dos possíveis efeitos dos compostos desreguladores endócrinos essa necessidade tem direcionado a uma demanda por métodos de ensaios in vitro e in vivo para identificar os efeitos biológicos dessa grande variedade de substâncias naturais e sintéticas presentes no meio ambiente ${ }^{31}$.

Alguns desses efeitos são citados na literatura encontrados em pássaros, peixes, tartarugas e crustáceos, tais como diminuição na eclosão de ovos, feminização e masculinização, problemas no sistema reprodutivo, disfunção da tireóide, diminuição da fertilidade, diminuição do sucesso da incubação, graves deformidades de nascimento, 
anormalidades metabólicas anormalidades de comportamento, efeitos que podem conduzir ao declínio da população ${ }^{31,33,38}$.

Em seres humanos esses efeitos incluem a redução da quantidade de esperma, o aumento da incidência de câncer de mama, de testículo e de próstata ${ }^{31}$, além da crescente frequência de anormalidades genitais em crianças, envolvendo testículos não descendidos (criptorquidia), pênis sumariamente pequenos, além de hipospadias, efeito no qual a uretra que transporta a urina não se prolonga até o final do pênis. Temos relatado também a aumento dos casos de endometrioses, uma doença na qual o tecido que normalmente recobre o útero se move, misteriosamente, para o abdome, os ovários, a vagina ou para o intestino, provocando crescimentos que causam dor, abundantes hemorragias, infertilidade e outros problemas ${ }^{32-33}$.

No Brasil, recentemente foram relatados alguns efeitos relacionados à exposição de desreguladores endócrinos no meio ambiente. Fernandez et $\mathrm{al}^{31}$. relataram a exposição de organismos marinhos a compostos orgânicos contendo estanho, o tributilestanho e o trifenilestanho, no litoral do Brasil (Rio de Janeiro, Fortaleza) e o desenvolvimento de caracteres sexuais masculinos em fêmeas de moluscos, fenômeno conhecido como “imposex".

Wilson Jardin et $a l .{ }^{39}$ realizaram um levantamento na bacia do rio Atibaia, onde foi monitorado 15 compostos, entre eles hormônios (17 $\beta$-estradiol, 17 $\alpha$-etinilestradiol, estrona, progesterona, levonorgestrel), os plastificantes (dietilftalato e dibutilfatalato), os surfactantes (4-nonilfenol e 4-octilfenol) e o bisfenol A e produtos farmacêuticos, tais como paracetamol, ácido acetil salicílico, diclofenaco e ibuprofeno. Em todas as campanhas realizadas foi encontrado algum composto em concentração elevada, demonstrando a grande quantidade de compostos descartados nessa bacia em concentrações acima das permitidas pelos órgãos de legislação.

\subsubsection{Bisfenol-A}

Bisfenol é um nome genérico empregado a um grupo de compostos pertencentes aos difenilalcanos $^{32}$, e têm o bisfenol A (BPA) como principal representante da classe ${ }^{33}$. Quimicamente o BPA é 4,4 '-di-hidroxi-2,2-difenilpropano ${ }^{40}$, sua estrutura é composta por dois anéis de fenol insaturados o qual é preparado pela condensação da acetona (onde resulta o sulfixo A). A reação é catalisada por ácido clorídrico $(\mathrm{HCl})$ ou resina de poliestireno sulfonada, como mostra a Figura 5. Tipicamente, um grande excesso de fenol costuma ser 
usado para garantir a condensação completa. Este monômero possui um grande atrativo econômico, o que justifica sua excessiva utilização em vários ramos atualmente ${ }^{41}$.

Figura 5 - Reação de formação de Bisfenol A.

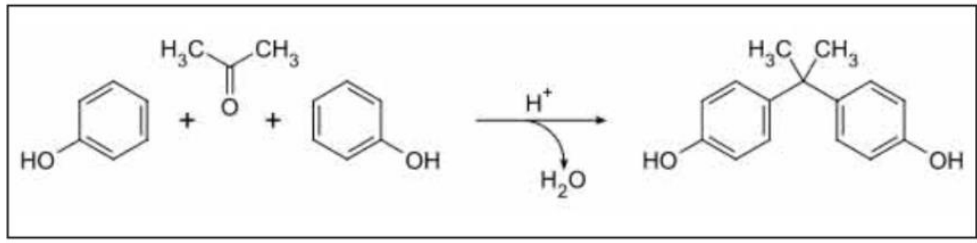

Os bisfenóis com grupo $\mathrm{OH}$ na posição para, e configuração angular, como apresenta o BPA, possuem condições adequadas para realizarem ligações de hidrogênio com os sítios receptores estrogênicos. O BPA é um desregulador endócrino que mimetiza o estrogênio, possui a capacidade de induzir uma resposta hormonal, mesmo em baixas doses, e pode causar o desequilíbrio no sistema endócrino ${ }^{42}$.

O BPA possui solubilidade em água de $120 \mathrm{mg} \mathrm{mL}^{-1}$, baixa pressão de vapor $(5,32 \mathrm{x}$ $10^{-6} \mathrm{~Pa}$ a $\left.25^{\circ} \mathrm{C}\right)$, baixa constante de Henry $\left(10^{-5}-10^{-6} \mathrm{~Pa} \mathrm{~m}^{3} \mathrm{~mol}^{-1}\right)$ e apresenta moderada partição entre água e ar. Mediante ao seu valor de $\mathrm{K}_{\mathrm{ow}}$ 3,4 tende a se acumular principalmente na matéria orgânica, apresentando possibilidade de adsorção por materiais particulados, além de serem lipofílicos e terem o potencial de bioconcentração. Essas características químicas mostram que o BPA está distribuído no meio ambiente entre ar, água, solo e sedimento e suas principais fontes de contaminação no meio ambiente são os efluentes industriais, os esgotos domésticos, bem como os lodos provenientes das ETE $^{32-34,43}$.

O tempo de meia-vida do BPA em águas superficiais varia de 1 a 150 dias, em águas subterrâneas esse tempo pode dobrar. No meio ambiente, sua decomposição é possível através de ação microbiológica ou por meio de fotólise pela absorção de energia em $290 \mathrm{~nm}$, sendo que esse processo ocorre de forma mais eficaz em matrizes com pH básico. Nos solos a meia vida do BPA pode variar de 1 a 180 dias aproximadamente e no ar esse valor é bem menor, entre 0,7 e 7,4 horas, pois nesse ambiente o processo de decomposição é acelerado pelos radicais hidroxilas ${ }^{43}$.

O BPA apresenta excelentes características físicas o que justifica sua larga utilização como material adjunto em plásticos, os quais são transparentes, leves, fortes e quase inquebráveis $^{40-41}$ e amplamente utilizados na indústria química para diversas finalidades como: na preparação de policarbonatos, brinquedos, lentes de contato, equipamentos médicos, mídias digitais (CDs e DVDs), telefones celulares, equipamentos eletrônicos, 
automobilísticos, utensílios domésticos, equipamentos esportivos, na produção de polímeros, resinas epóxi e resinas de poliéster-estireno insaturadas, é utilizado também como fungicida e agente retardante de chama, no uso como estabilizante na produção de plásticos, inclusive embalagens de alimentos (produção de mamadeiras, embalagens retornáveis de água, como revestimento interno nas latas de alumínio usadas em bebidas como cervejas e refrigerantes), como selante dentário e agente antioxidante ${ }^{32-33,40-41}$.

A limitação quanto à utilização do BPA está relacionada ao alto volume do composto que é produzido mundialmente. A principal aplicação do BPA é como monômero na produção de policarbonato ( $71 \%$ do que é produzido destina-se a esse fim), e resinas-epóxi (27\%), além de aditivos de resinas de poliéster-estireno insaturadas e retardantes de chama ${ }^{43}$.

Sua presença no meio ambiente é devido aos processos de produção e manufatura do BPA, aos despejos dos efluentes industriais sem tratamento adequado, e a lixiviação dos produtos finais de consumo, que pode ocorrer quando ocorre a quebra do polímero ${ }^{31}$, acarretando assim a acumulação desse composto, que é resistente à biodegradação ${ }^{43}$. Assim, os seres humanos podem rotineiramente ingerir pequenas quantidades de BPA e seus efeitos na saúde humana tornaram-se uma preocupação crescente ${ }^{40}$.

Durante mais de 50 anos, o BPA foi comercializado como importante monômero, utilizado para a produção de policarbonatos, polissulfona, vários plásticos e resinas epóxi ${ }^{42}$. A produção do BPA em 2007 foi estimada em 3,8 milhões de toneladas ${ }^{44}$. O BPA pode ser encontrado em águas naturais como consequência de efluentes industriais não tratados, e é muito perigoso ao ecossistema aquático, devido à sua capacidade de interagir com receptor de estrogênio. Assim, as leis reguladoras têm limitado a sua presença em organismos aquáticos em um intervalo de $1,0-15,0 \mathrm{mg} \mathrm{mL}^{-1} 42$.

A atividade estrogênica do BPA é relatada em estudos desde $1936^{45}$. O BPA se mostrou capaz de estimular a síntese e proliferação de células cancerígenas, desalojando o $17 \beta$-estradiol do seu sítio receptor. Outros estudos realizados em ratos mostraram que baixas concentrações de BPA, cerca de $2 \mu \mathrm{g} \mathrm{kg}^{-1} \mathrm{em}$ doses diárias, foram suficientes para provocarem efeitos nos órgãos sexuais e com doses diárias de $20 \mu \mathrm{g} \mathrm{kg-1}$ houve redução no número de espermatozoides dos ratos. Estudos realizados em peixes da espécie Pimephales promelas, expostos a concentrações entre 1 e $1280 \mu \mathrm{g} \mathrm{L} \mathrm{L}^{-1}$ de bisfenol A, mostraram uma redução na fertilidade desses animais, a qual aumentou com o passar das gerações ${ }^{35,43}$. E em estudos in vitro foi demonstrado que o BPA é uma substância com ação estrogênica fraca, aproximadamente 1000-15000 vezes menos ativa que o estradiol ou o estriol. 
A atividade estrogênica do BPA foi descoberta em 1984 quando pesquisadores da Universidade de Stanford identificaram uma proteína capaz de se ligar ao estrogênio em levedura e iniciaram estudos para avaliar a existência de um ligante endógeno ligado a esta proteína. Após a verificação de que a levedura estudada produzia $17 \mathrm{~b}$ estradiol $^{46}$, os pesquisadores relataram que a atividade estrogênica não era proveniente da levedura, mas de origem da água autoclavada em frasco de policarbonato ${ }^{47}$, a substância encontrada foi estudada, purificada e identificada como bisfenol A. Aproximadamente $2-3 \mathrm{mg} \mathrm{L}^{-1}$ foram detectados na água autoclavada, e os pesquisadores conseguiram demonstrar que o BPA satisfaz todos os critérios para ser classificado com substância estrogênica, com dose mínima efetiva de $10-20 \mathrm{nmol} \mathrm{L}^{-1} 33$.

Um biomarcador usado para avaliar a exposição de alguns organismos a substâncias com atividade estrogênica é a vitelogenina, a determinação é feita através dos níveis de vitelogenina presentes no plasma sanguíneo do organismo estudado. É uma proteína que desempenha um importante papel no sistema reprodutivo de vertebrados ovíparos fêmeas. Ela é sintetizada no fígado, regulada por estrogênio e transportada através do sangue para os ovários, onde serão incorporadas aos óvulos e são responsáveis pelo crescimento. O gene responsável pela produção do vitelogenina está presente em organismos machos, mas em condições normais não é expresso, devido à baixa concentração de estrogênio no sangue. Assim, o aumento de vitelogenina no plasma de um organismo pode representar uma evidência da exposição às substâncias com atividade estrogênica ${ }^{43}$.

$\mathrm{Na}$ literatura encontramos relatos de alguns organismos aquáticos que respondem ao aumento na síntese de vitelogenina como resposta à exposição a determinadas concentrações de estrogênios. Um experimento realizado com a espécie de tartarugas Chrysemys picta, demostrou que as tartarugas fêmeas apresentavam alto nível de vitelogenina no plasma, ao serem expostas a estrogênios, resultando em alterações no sistema reprodutivo. Outros estudos mostraram que vários xenoestrogênios tais como bisfenol-A e os alquilfenóis, apresentam condições de estimular a produção de vitelogenina, principalmente em peixes, onde esse tipo de ensaio é comumente realizado, alterando o desenvolvimento natural das espécies $^{48}$.

A produção de BPA no Brasil gera cerca de 25 mil toneladas por ano do composto, e a Rhodia é a única fabricante. O destino final do BPA produzido é exclusivamente industrial e utilizado para fabricação de resinas epoxy e de policarbonato. 
Atualmente, a ANVISA (Agencia Nacional de Vigilância Sanitária) é o órgão que regula as embalagens de alimentos no Brasil, a agência determinou que as normas de utilização do BPA no País estão padronizadas seguindo as normas de segurança da União Europeia. O uso da substância é aprovado com restrição de $0,26 \mathrm{mg} \mathrm{kg}^{-1}$, e seu uso é considerado seguro dentro dessas normas. A dose de referência para exposição oral crônica é estabelecida em $0,05 \mathrm{mg} \mathrm{kg}^{-1}$ de peso corporal/dia, pela Agência de Proteção ao Meio Ambiente dos Estados Unidos para alimentos. Um limite específico para a migração de BPA proveniente de embalagens foi fixado em 3,00 $\mathrm{mg} \mathrm{Kg}^{-1}$ de alimento. Considerando as normas da União Europeia para poluentes orgânicos em águas, o limite é de $0,1 \mathrm{ng} \mathrm{mL}^{-1}$ para $\mathrm{BPA}^{33}$.

Em 2005, o Conselho Nacional do Meio Ambiente (Conama) aprovou a Resolução 357, que trata da classificação dos corpos d’água e estabelece padrões de lançamento de efluentes, mas o documento não determina valores máximos e BPA em águas, efluentes industriais ou de estações de tratamento de esgoto ${ }^{33}$.

Assim, a descoberta e determinação da presença dos desreguladores endócrinos no meio ambiente têm estimulado muitos pesquisadores a estudar e desenvolver métodos eficazes para a identificação desses compostos na forma de traço e no desenvolvimento de métodos analíticos eficazes na sua determinação.

Vários métodos analíticos tem se mostrado sensíveis na determinação do BPA, e as técnicas cromatográficas são amplamente utilizadas para este fim e aceitas pelos órgãos de regulação como métodos padrão para análise $e^{49-55}$.

Cromatografia em fase gasosa acoplada com espectrometria de massa (GC-MS) fornece informação analítica útil para a identificação e quantificação destes compostos em águas residuais e lodo de esgoto, este método foi aplicado para determinação desses compostos em amostras reais. GC-MS também tem sido reportado para análise BPA em água e sedimentos, este método possibilitou obter limites de detecção da faixa de 0,01 a 0,49 ng $\mathrm{L}^{-1}$ em água e de 0,05 a 0,14 ng g $^{-1}$ em sedimento $^{33,40,42,56}$.

A cromatografia líquida de alta eficiência (HPLC do inglês high performance liquid chromatography) é outra técnica muito utilizada para análise de BPA, encontramos na literatura essa técnica acoplada a vários detectores, como o ultravioleta (UV) ${ }^{32}$, a fluorescência $(\mathrm{FL})^{34}$, detecção eletroquímica $(\mathrm{DE})^{35}$ e também espectrometria de massa $(\mathrm{MS})^{36}$.

O HPLC-MS ${ }^{41-42}$, HPLC com detecção por fluorescência ${ }^{43}$, e HPLC com detecção eletroquímica pelo método coulométrico $(\mathrm{ECD})^{42,56}$ são atualmente usados para BPA no soro 
ou plasma. O HPLC-ECD tem alta sensibilidade e seletividade, sem a necessidade da etapa de derivatização. Além disso, o fluxo através de eletrodos de grafite poroso de carbono não necessita de manutenção por períodos prolongados de tempo mostrando-se adequados para análise de rotina ${ }^{57}$.

O HPLC com detector de fluorescência (FL) (HPLC/FL) é descrita para determinação de BPA em peixes enlatados. A concentração de BPA foi determinada em 19 atuns, sardinha e cavala. Nas diferentes matrizes analisadas o limite de detecção variou de $0,2 \mathrm{ng} \mathrm{g}^{-1}$ (sardinha) a $1,8 \mathrm{ng} \mathrm{ml}^{-1}$ (óleo) e os limites de quantificação de $0,4 \mathrm{ng} \mathrm{g}^{-1}$ a $3,8 \mathrm{ng} \mathrm{mL}^{-1}$, respectivamente.

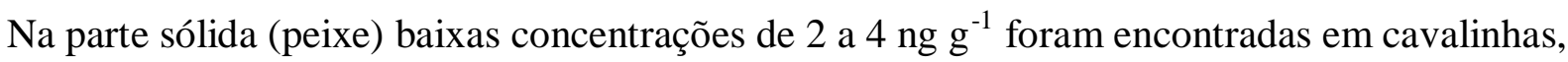
sendo a concentração mais alta encontrada em atum de $59 \mathrm{ng} \mathrm{g}^{-1}$. No entanto, em todas as amostras analisadas a concentração apresentava-se menor que a estabelecida pela Comissão da União Europeia $\left(0,6 \mathrm{mg} \mathrm{kg}^{-1}\right)^{58}$.

Outra técnica relatada para a determinação do BPA é a cromatografia líquida com ionização por eletrospray acoplada a espectrometria de massas (LC-ESI-MS) ${ }^{59-60}$. As matrizes analisadas foram ovos, com limites de detecção de $0,10 \mu \mathrm{g} \mathrm{kg}^{-1}$ e os limites de quantificação de $0,10 \mu \mathrm{g} \mathrm{kg}^{-1}$.

Assim através da pesquisa realizada na literatura encontramos diversos métodos para a determinação e quantificação do BPA, no entanto, os procedimentos cromatográficos, que são os mais utilizados e aceitos, mas requerem um intenso tratamento da amostra. Essa etapa torna os métodos dispendiosos, demorados, e requerem operadores especializados. Fora essas características, o método ainda necessita utilizar solventes orgânicos, a derivação do sistema para melhora da resposta, e equipamentos de alto custo, e apresentam dificuldade em trabalhar com amostras complexas reais, pois essas amostras diminuem a sensibilidade.

Mediante a todas essas limitações, muitos cientistas buscam encontrar um método para uso de rotina que seja rápido, sensível, reprodutível, de baixo custo, relativamente "verde", e pode, simultaneamente, detectar traços de composto estrogênicos ${ }^{56}$.

Outro ponto que continua sendo um limitante para muitas técnicas de análises é o efeito de matriz, uma vez que muitas matrizes apresentam-se em formas complexas, como lamas, drogas farmacêuticas, gorduras, proteínas, sais, açúcares, ou material não desejado quando estamos nos referindo à determinação analítica.

A concentração de um analito de ser levada em consideração para a determinação do seu limite de quantificação, especialmente quando a quantidade de amostra disponível para testes é limitada. Além disso, as matrizes de amostra podem dificultar a detecção mediante ao 
aumento do sinal de fundo, e a soma de todas essas limitações causam ao sistema diminuição na precisão e na reprodutibilidade na determinação do analito ${ }^{56}$.

Como alternativa a todas as características descritas acima, podemos citar os sensores eletroquímicos, os quais possuem excelente seletividade e especificidade nas determinações resultante da oxi-redução das espécies analíticas de interesse em um potencial específico, permite miniaturização do sistema, seletividade decorrente dos processos de oxi-redução do analito em eletrodo de trabalho feito com material específico, análise em tempo curto, grande sensibilidade e baixos limites de detecção resultante das técnicas de pré-concentração e modos de aquisição de sinal que proporciona ambiente com baixo sinal de fundo, baixo consumo de energia, não utilização de solventes orgânicos e equipamento de baixo custo $^{33}$.

O BPA pode ser oxidado para exibir uma atividade eletroquímica, uma vez que contém grupos hidroxilo fenólicos ${ }^{37}$. No entanto, sua determinação direta através da utilização de um sensor eletroquímico é pouco citada na literatura, uma vez que sua resposta em um sensor eletroquímico é muito pequena e sem definição, apresenta potencial de oxidação relativamente alto, o que resulta em um aumento da corrente de fundo e diminui a sensibilidade da técnica. Outro fator que influencia negativamente o sinal eletroquímico do BPA é que sua oxidação, a qual pode causar a formação de um filme pelo fenômeno de eletropolimerização, causando a desativação de eletrodos de carbono vítreo e de metais nobres. Assim, para superar estas desvantagens, os pesquisadores têm buscado novos materiais, que possam melhorar a sensibilidade, o tempo de resposta e causar o mínimo de deposição da oxidação do $\mathrm{BPA}^{40}$.

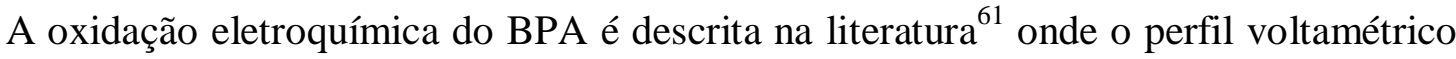
é obtido com excelente resolução, mas o produto da reação estudada inativa o eletrodo de carbono vítreo utilizado no experimento. Estudos mostram a tentativa de se analisar o BPA em platina, fibra de carbono, com a utilização de nanotubos de carbono sobre a superfície do eletrodo de trabalho, mas sua aplicação não é trivial, e devido a supressão do sinal analítico, a construção da curva de calibração torna-se um método impreciso ${ }^{42}$.

Estudos mostram que um método eletroquímico eficiente para BPA é baseado em biosensores, esses estudos mostram a possibilidade de se determinar BPA em um nível de concentração baixa, numa solução aquosa, mas o método requer o emprego de enzimas sobre a superfície do eletrodo de trabalho ${ }^{42,62-64}$.

A detecção amperométrica do BPA também é descrita na literatura por WU et al. $2008^{65}$, o estudo foi aplicado em amostras de esgoto. A análise mostrou a presença de BPA 
em um nível de concentração de $1 \mathrm{~g} \mathrm{~L}^{-1}$ e o limite de detecção obtido pra BPA foi de $3,5 \times 10^{-6}$ $\mathrm{g} \mathrm{mL}^{-1}$. Outro estudo para a determinação de BPA foi baseado na modificação do eletrodo de carbono vítreo com multi camadas de nanotubos de carbono feito por LU et al. $2004^{66}$. Essa modificação proporciona ao eletrodo um bom perfil eletroquímico para a reação de oxidação, tendo o pico de oxidação no potencial de $0,58 \mathrm{~V}$. O método desenvolvido apresentou limite de detecção de 2,0 x $10^{-8}$ mol L ${ }^{-1}$ e sua aplicação foi realizada para determinação de BPA em amostras residuais de plástico.

Um imuno sensor desenvolvido por Rahman et al. $2007^{67}$ para determinação de BPA, o qual é preparado através da utilização do anticorpo policolonas e o grupo ácido carboxílico funcionalizado sobre uma nanopartícula composta por um polímero condutor. Os autores obtiveram um limite de detecção de $0,3 \mathrm{ng} \mathrm{mL}^{-1}$, em condições laboratoriais. O imunosensor proposto foi aplicado para determinação de BPA em amostras de soro humano através do método da adição de padrão.

Outra aplicação para a determinação de BPA foi proposta por Huang et al. em $2007^{68}$, e o sensor foi aplicado em amostras de águas residuárias. Sobre a superfície do eletrodo de carbono vítreo é formado um filme compósito de acetileno preto - dihezadecil hidrogeno fosfato (do inglês Acetylene Black - dihezadecil hydrogen phosphate AB-DHP), onde a comparação entre o eletrodo sem modificação e o modificado não distinguiram quanto ao valor de corrente de pico de oxidação, mas o potencial de oxidação foi menor para o eletrodo modificado sugerindo que o eletrodo pode ser útil na determinação do BPA. Para o método desenvolvido o limite de detecção foi de $6,0 \times 10^{-9} \mathrm{~mol} \mathrm{~L}^{-1}$.

Mesmo possuindo muitos estudos sobre o tema na literatura, a grande maioria apresentam problemas cinéticos, inativação do eletrodo ou baixo efeito eletrocatalítico, o que inviabiliza a aplicação dos eletrodos propostos para amostras com baixas concentrações do $\mathrm{BPA}^{33}$.

Além da atenção sobre a questão de determinação do BPA no meio ambiente e sua ação sobre os organismos que possuem o sistema estudado, muitas publicações referem-se sobre o tema proposto demonstrando diferentes ponto de vista defendidos em prol e contra a utilização destes compostos em suas aplicações, uma vez que o BPA é hoje aplicado em praticamente todo o tipo de embalagem destinada a alimentos entre outras aplicações citadas acima. A reflexão presente destina-se desde o banimento de seu uso como aditivo para alguns plásticos até o estabelecimento de um limite máximo admissível que não represente risco à saúde humana ${ }^{41}$. 


\section{BJETIVOS}

O objetivo geral desta dissertação é desenvolver e caracterizar eletrodos de ouro recoberto com camada auto-organizadas de nanotubos de carbono alinhados. Os CNTs serão imobilizados sobre SAMs de ssDNA para a detecção de bisfenol A, um importante interferente endócrino. Este objetivo geral pode ser detalhado nos seguintes itens:

- Desenvolver uma superfície auto-organizada e alinhada a partir de um filme híbrido de SWCNT-SAM de ssDNA via interação tiol ouro.

- Caracterizar o alinhamento dos CNTs nas superfícies dos eletrodos desenvolvidos por microscopia de força atômica (AFM).

- Realizar uma comparação eletroquímica dos sensores construídos pela técnica de alinhamento dos CNTs com a formação de SAMs com ssDNA. A comparação será realizada utilizando voltametria cíclica e a espectroscopia de impedância eletroquímica (EIS) no par redox $\left[\mathrm{Fe}(\mathrm{CN})_{6}\right]^{3-/ 4-}$.

- Estudar o comportamento eletroquímico dos interferentes endócrino, Bisfenol-A sobre a superfície dos eletrodos desenvolvidos utilizando técnicas eletroquímicas.

- Otimizar os parâmetros da técnica de voltametria de pulso diferencial (DPV) e a voltametria de onda quadrada (VOQ) para a detecção eletroquímica do interferente endócrino estudado. 


\section{METODOLOGIA}

\subsection{Reagentes e soluções}

Bisfenol A (BPA) foi obtido da Sigma-Aldrich (Alemanha) em grau analítico. O ácido sulfúrico 98,0 \%, o ácido nítrico 65,0 \% têm procedência Mallinckrodt e Qhemis, respectivamente. O peróxido de hidrogênio 30,0 \% (m:v) foi adquirido da Tec-Lab. O álcool etílico absoluto anidro (etanol) foi obtido da J.T. Baker. SWCNT pureza 98\% foi adquirido a partir de NanoLab (EUA) e o ssDNA tiol-terminado (5-HS-TGG-GGT-TTA-TGG-AAATTGGAA-3 ') foi adquirido de Sinapse Biotecnologia (Brasil).

Os reagentes, $\mathrm{HCl} 36,0 \%, \mathrm{AgNO}_{3}, \mathrm{KCl}$ e $\mathrm{Hg}_{2} \mathrm{Cl}_{2}$, e mercúrio metálico, utilizados para o preparo dos eletrodos de referências de $\mathrm{Ag} / \mathrm{AgCL} / \mathrm{KCl} 3 \mathrm{~mol} . \mathrm{L}^{-1}(\mathrm{Ag} / \mathrm{AgCl}$ ) e Eletrodo Saturado de Calomelano (SCE) foram obtidos da J.T.Baker.

O eletrólito de suporte era solução de tampão de fosfato (PBS) $0,2 \mathrm{~mol} \mathrm{~L} \mathrm{~L}^{-1}$. Todos os eletrólitos foram preparados com água ultrapura purificado na Barnested Nanopure System, com resistividade de $18,2 \mathrm{M} \Omega \mathrm{cm}^{-1}$.

\subsection{Materiais e instrumentos para medidas eletroquímicas}

\subsubsection{Medidas Eletroquímicas}

As medidas eletroquímicas, voltametria cíclica, voltametria de onda quadrada e a voltametria de pulso diferencial foram realizadas em um potenciostato - galvanostato PGSTAT30/Autolab® utilizando o software GPES.

\subsubsection{Medidas de Espectroscopia de Impedância Eletroquímica}

Os experimentos de Espectroscopia de Impedância Eletroquímica (EIE) foram realizados utilizando os mesmos materiais das medidas voltamétricas. Assim um potenciostato PGSTAT30/Autolab® controlado pelo software FRA foi utilizado para as medidas experimentais. Os espectros de plano complexo foram analisados com o software 
Electrochemistry-ZView2. As medidas foram realizadas em temperatura ambiente após desaeração da solução por 10 minutos com borbulhamento de $\mathrm{N}_{2}$.

\subsubsection{Célula eletroquímica}

Para as medidas eletroquímicas utilizou-se uma célula eletroquímica de vidro borossilicato de compartimento único com $10 \mathrm{~mL}$ com tampa de Politetrafluoretileno (PTFE) como é representado na Figura 6. Os três eletrodos utilizados foram um contra-eletrodo de

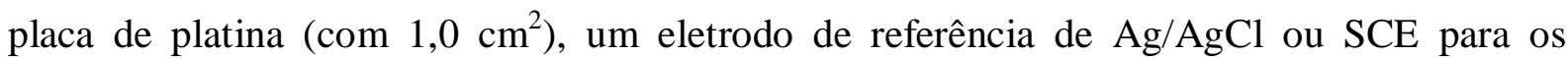
experimentos realizados em meio alcalino, e um eletrodo de trabalho de ouro com área geométrica de $0,04 \mathrm{~cm}^{2}$ da superfície exposta à solução.

Figura 6 - Representação esquemática da célula eletroquímica utilizada durante os experimentos.

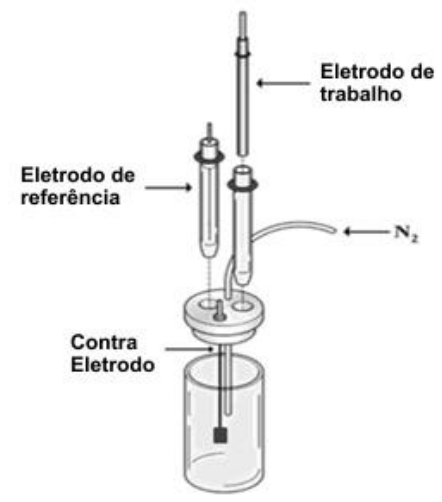

\subsubsection{Eletrodo de referência}

$\mathrm{O}$ eletrodo de referência $\mathrm{Ag} / \mathrm{AgCl}$ foi construído utilizando um fio de prata, previamente polido com lixas 600 e anodizado em uma solução de $\mathrm{HCl} \mathrm{0,3} \mathrm{mol} \mathrm{L-1}$, e após esta etapa é guardado em um reservatório próprio completamente preenchido com solução de $\mathrm{KCl}$ 3,0 mol L ${ }^{-1}$ contendo alguns cristais de AgNO3. A anodização do fio de prata em solução de $\mathrm{HCl}$ é necessária para formar um filme de cloreto de prata na superfície do fio.

Para a construção do eletrodo de calomelano saturado (SCE), adicionou-se uma quantidade suficiente de mercúrio em um tubo de vidro contendo um fio de platina 
(responsável pelo contato elétrico). Em seguida preparou-se uma pasta, com a mistura de cloreto mercuroso, mercúrio e algumas gotas de solução de $\mathrm{KCl}$ saturado. A pasta foi colocada no tubo contendo mercúrio deixando um espaço para vedação com fibra de amianto. Após essa etapa inseriu-se o tubo contendo mercúrio e pasta de cloreto mercuroso em um reservatório próprio contendo solução saturada de $\mathrm{KCl}$, cuidando para que não se formassem bolhas de ar.

\subsubsection{Contra-eletrodo}

Utilizou-se como contra eletrodo uma placa de platina com $1,0 \mathrm{~cm}^{2}$ de área geométrica, soldada a um fio de platina e embutido em tubo de vidro. Antes dos experimentos a placa de platina e a haste era aquecidas em chama redutora e lavadas com água ultrapura.

\subsubsection{Eletrodos de trabalho}

Os eletrodos de trabalho foram confeccionados embutindo fios de ouro com 2,0 mm de diâmetro em um cilindro de PTFE. Foi feito no cilindro de PTFE um orifício de 1,5 mm de diâmetro, e aqueceu-se em banho de água quente, da mesma maneira que o fio de Au foi mantido em água pura com gelo. Após um período de 20 minutos o fio de ouro foi retirado do banho de gelo e embutido no PTFE ainda aquecido.

Uma vez prontos e a temperatura ambiente, os eletrodos foram polidos com lixas d'água (grids 600 - 1200 -2000 e 4000), até a exposição de um disco do metal.

\subsection{Instrumentação Geral}

Utilizou-se uma balança analítica Mettler Toledo da Micronal S/A modelo AL 204 para pesagens.

Para ajustes e medidas de $\mathrm{pH}$ utilizou-se um pH-metro Qualxtron modelo 8010.

O ultrassom utilizado na etapa de limpeza dos eletrodos de ouro foi adquirido da Unique (Ultrasom MaxiClean modelo 1450 com frequência de $25 \mathrm{kHz}$ ). 


\subsection{Procedimentos Experimentais}

\subsubsection{Pré-tratamento da superfície dos eletrodos de Au}

O procedimento de limpeza da superfície do eletrodo de Au foi realizado, seguindo uma parte da metodologia descrita por Coelho ${ }^{15}$. O procedimento é dividido em quatro etapas, (i) redução eletroquímica de contaminantes orgânicos em meio alcalino, (ii) polimento mecânico e (iv) polimento eletroquímico, e foram utilizados as etapas ii e iv.

O polimento mecânico foi realizado com a ajuda de lixas d'água grid 600, 1200, 2000 e 4000, seguidos de um polimento em suspensão de alumina (1:5 de alumina : água) utilizando tecido de polimento como base para fricção. O polimento é repetido até que a superfície apresente um aspecto espelhado. A cada etapa realizada, seja da lixa d'água ou de alumina, todo o conjunto foi lavado com água ultrapura.

A etapa de limpeza eletroquímica foi realizada utilizando a voltametria cíclica, onde o potencial era variado de 0,0 a 1.8 Volts (vs $\mathrm{Ag} / \mathrm{AgCl}$ ) utilizando como eletrólito suporte solução de $\mathrm{H}_{2} \mathrm{SO}_{4} 0,1 \mathrm{~mol} \mathrm{~L}^{-1}$ e variando a velocidade de varredura com 100 ciclos a $1 \mathrm{~V} \mathrm{~s}^{-1}$, 50 ciclos a $0,5 \mathrm{~V} \mathrm{~s}^{-1}, 25$ ciclos a $0,25 \mathrm{~V} \mathrm{~s}^{-1}$ e 10 ciclos a $0,1 \mathrm{~V} \mathrm{~s}^{-1}$. A cada etapa terminada o eletrólito suporte era trocado e o todo o conjunto eletroquímico lavado com água.

\subsection{Procedimento para Modificação do eletrodo}

\subsubsection{Modificação do eletrodo de trabalho}

O alinhamento de SWCNT sobre a superfície Au foi baseado no trabalho de Zheng et al. $2003^{27}$. Para este estudo, 1,0 mg SWCNT funcionalizado foi misturado com 1,0 mL de uma solução de ssDNA de $1,0 \mu \mathrm{mol} \mathrm{L}^{-1}$, e o ssDNA foi preparado em $0,1 \mathrm{molL}^{-1}$ de PBS contendo cloreto de sódio a 10\% (v / v). Em seguida, a mistura foi sonicada usando uma sonda de ultra-som por $45 \mathrm{~min}$ e depois centrifugada a $10000 \mathrm{rpm}$ por $30 \mathrm{~min}$. Finalmente, um eletrodo de Au previamente limpo foi imerso na solução de sobrenadante e monocamadas auto-organizadas (SAM), que consistem de ssDNA/SWCNT foram formadas durante $24 \mathrm{~h}$ numa sala refrigerada a $4{ }^{\circ} \mathrm{C}$.

Um experimento realizado com SWCNT disperso sobre a superfície do eletrodo de Au foi preparado por mistura de 1,0 mg de SWCNT e 1,0 mL de PBS. A suspensão foi colocada num banho de ultra-sons durante 30 minutos. Em seguida, $10 \mu \mathrm{L}$ da dispersão foi adicionado sobre a superfície do eletrodo de Au. O filme formado foi seco em temperatura ambiente. 


\subsubsection{Funcionalização do CNTs}

O método de funcionalização consistiu em misturar $50 \mathrm{mg}$ de SWCNT em $200 \mathrm{~mL}$ de uma solução ácido nítrico $\left(\mathrm{HNO}_{3}\right) 5 \mathrm{~mol} \mathrm{~L}{ }^{-1}$. Essa mistura foi agitada por 6 horas. Após esse período de agitação realizou-se o procedimento de filtração dos SWCNT e a lavagem foi feita com água ultrapura. Os SWCNT foram secos em estufa por 12 horas a $70{ }^{\circ} \mathrm{C}$.

\subsection{Caracterização morfológica e estrutural dos CNTs funcionalizados}

Com o objetivo de avaliar a modificação da superfície do eletrodo de $\mathrm{Au}$, foi realizado medidas voltamétricas, voltametria cíclica (VC) e voltametria de onda quadrada (VOQ) com o três sistemas, o par $\mathrm{Fe}(\mathrm{CN})_{6}{ }^{+3} / \mathrm{Fe}(\mathrm{CN})_{6}{ }^{+4}$ e o Bisfenol-A.

Para complementar o estudo, foi realizado Microscopia de Força Atomica (AFM) modelo Nanosurf ${ }^{\circledR}$ Easyscan2 AFM System Versão 2.2, no modo não contato tapping mode com long cantilever. Utilizando o software Nanosurf EasyScan 2.

\subsection{Estudo do comportamento eletroquímico do Bisphenol-A}

\subsubsection{Estudo do mecanismo redox do Bisphenol-A}

Avaliou-se o mecanismo de oxidação e redução do Bisphenol-A a partir de estudos da variação de $\mathrm{pH}$ e variação de velocidade de varredura de potenciais, empregando voltametria cíclica. As medidas foram realizadas em tampão fosfato $0,2 \mathrm{~mol} \mathrm{~L}^{-1}$. A faixa de potencial estudada variou de 0,0 a $0,9 \mathrm{~V}(\mathrm{vs} \mathrm{Ag} / \mathrm{AgCl})$ e a velocidade de varredura de 5 a $200 \mathrm{mV} \mathrm{s}$. Utilizou-se uma concentração de $1,0 \mathrm{mmol} \mathrm{L}^{-1}$ do BPA para ambos os estudos. A análise dos dados obtidos foi realizada considerando as repostas de corrente de pico e potencial de pico.

\subsubsection{Otimização dos parâmetros de análise para a construção da curva analítica do Bisphenol-A}

Utilizou-se como técnica de análise a voltametria de pulso diferencial (VPD). Os parâmetros da técnica como a amplitude de pulso (A), incremento de potencial de varredura $(\Delta \mathrm{E})$ e frequência de pulso $(f)$, foram avaliados e otimizados em solução de tampão fosfato 0,2 mol L ${ }^{-1} \mathrm{pH}$ 6,0 contendo 1,0 mmol L $\mathrm{L}^{-1}$ de BPA. 
Para a determinação do limite de detecção e limite de quantificação construiu-se uma curva analítica utilizando a VPD com os parâmetros otimizados. Utilizou-se o eletrodo de trabalho modificado contendo ssDNA/SWCNT.

\section{RESULTADOS E DISCUSSÃO}

\subsection{Caracterização da modificação da superfície do ouro com o nanohibrido SSDNA/SWCNT}

As características morfológicas dos eletrodos foram realizadas por microscopia de força atômica. A Figura 7A apresenta uma imagem típica do eletrodo de ouro, o qual apresenta uma superfície lisa e plana. Com base em análises de topografia, mostrada no inset da Figura 7A da superfície do $\mathrm{Au}$, foi determinado a rugosidade de vários pontos da superfície estudada, obtendo ao final o desvio padrão médio da rugosidade, encontrando o valor de 1,95 nm. A Figura 7B mostra a mesma superfície modificada com uma monocamada auto-montada formada por ssDNA/SWCNT. Nesta microscopia foi observado um aumento da rugosidade, quando comparada com a superfície de ouro sem modificação. Além disso, observou-se que os SWCNTs foram empacotados e alinhados verticalmente. Com base na topografia (detalhe na Figura 7B) o desvio padrão médio da rugosidade foi calculado e obtido o valor de 47,5 nm, enquanto que a altura média para o SWCNTs foi encontrada a partir do gráfico de topografia, com valor de $260,3 \mathrm{~nm}$, com um desvio padrão relativo de $19,9 \%$.

O comportamento eletroquímico do eletrodo de ouro liso e modificado com o hibrido ssDNA/SWCNT foi caracterizado utilizando voltametria cíclica. Os experimentos foram realizado em meio de $\mathrm{Na}_{2} \mathrm{SO}_{4} 0,1 \mathrm{~mol} \mathrm{~L}^{-1}$ contendo $\mathrm{K}_{3} \mathrm{Fe}(\mathrm{CN})_{6} 5,0 \mathrm{mmol} \mathrm{L}^{-1}$, com velocidade de varredura de potencial de $50 \mathrm{mVs}^{-1}$. A Figura 8 mostra os voltamogramas cíclicos para o eletrodo de $\mathrm{Au}$ (linha preta) e o eletrodo de Au/ssDNA/SWCNT (linha vermelha). 
Figura 7- Imagens de AFM dos eletrodos: (A) Au sem modificação, (B) Au/ssDNA/SWCNT. Detalhe: Gráficos de Topografia.
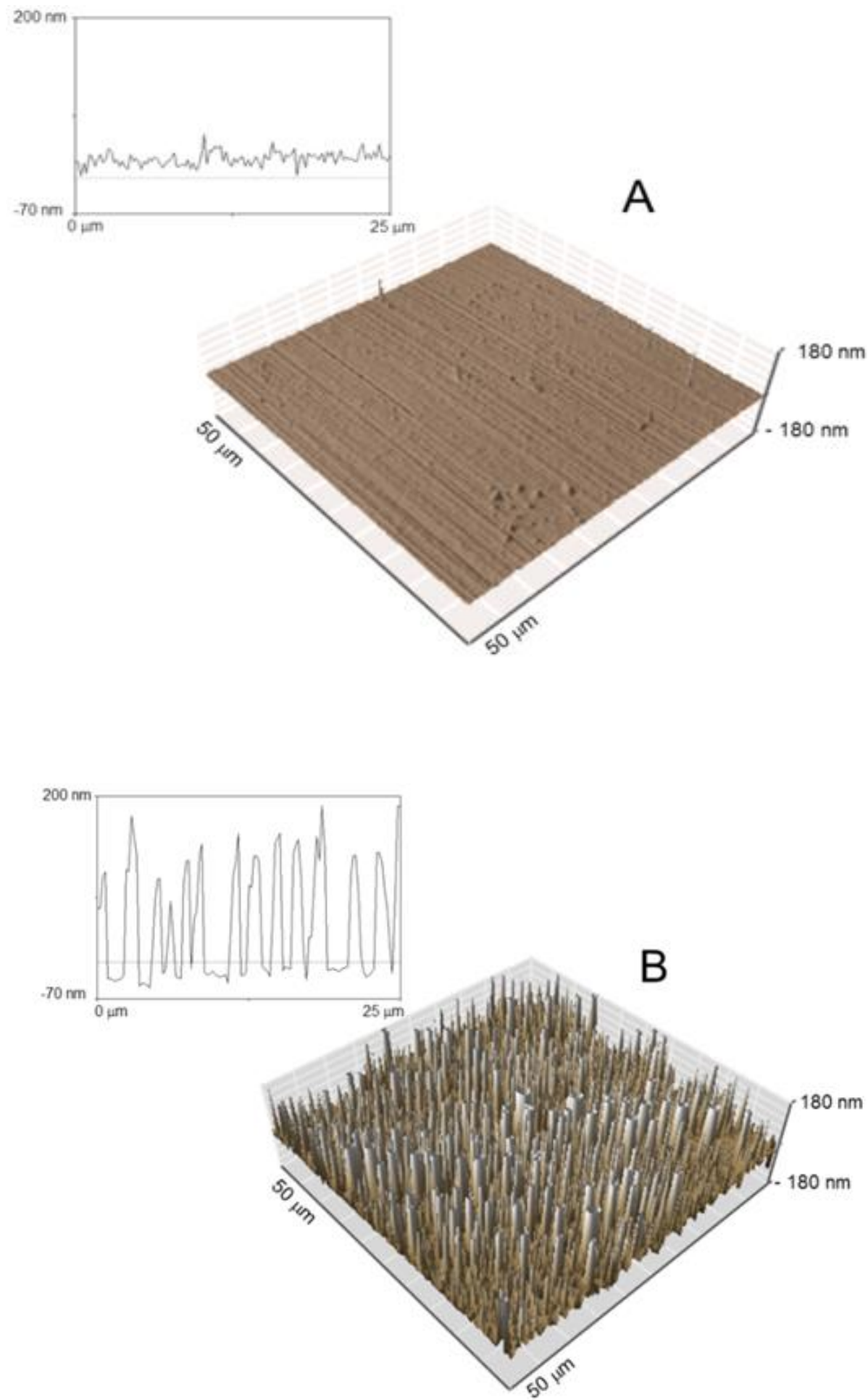
Figura 8- Voltamogramas cíclicos de estado estacionário para os eletrodos de $\mathrm{Au}$ : (-) $\mathrm{Au}$ e (-) $\mathrm{Au} / \mathrm{DNA} / \mathrm{SWCNT}$ funcionalizados em $\mathrm{Na}_{2} \mathrm{SO}_{4} 0,1$ mol L ${ }^{-1}$ contendo $\mathrm{Fe}(\mathrm{CN})_{6}{ }^{3-/ 4-}$ 5,0 mmol L ${ }^{-1}$ cada, a $50 \mathrm{mVs}^{-1}$.

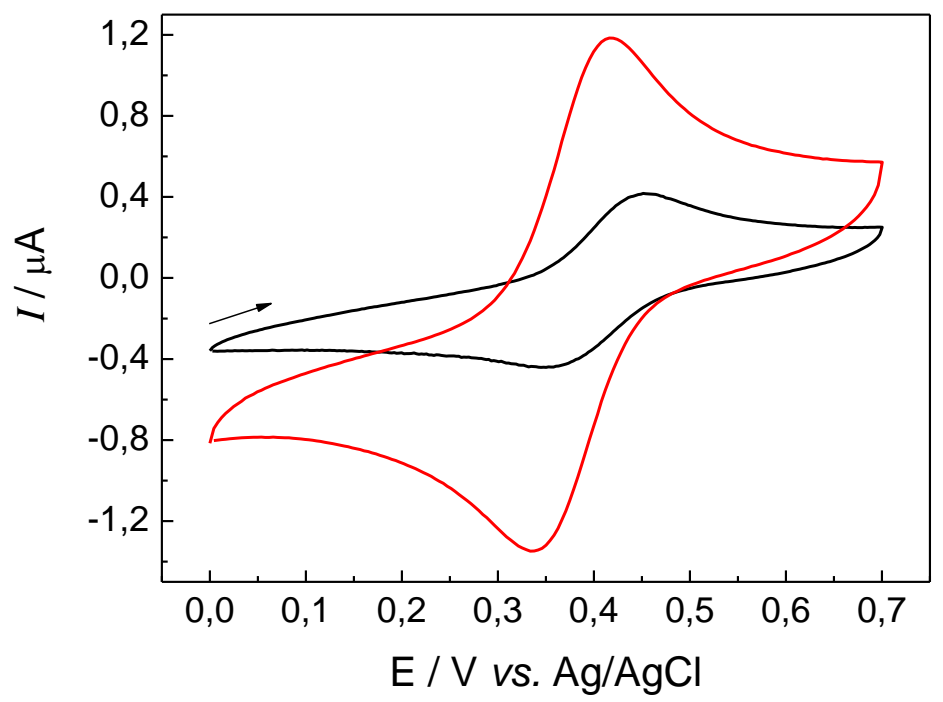

Comparando o eletrodo de Au/ssDNA/SWCNT com o eletrodo de Au sem modificação pode ser observado que a reversibilidade do par redox $\mathrm{Fe}(\mathrm{CN})_{6}{ }^{3-} / \mathrm{Fe}(\mathrm{CN})_{6}{ }^{4-}$ é maior para o eletrodo modificado com ssDNA/SWCNT $\left(\Delta \mathrm{E}_{\text {pico }}=80 \mathrm{mV}\right)$ quando comparado ao eletrodo de $\mathrm{Au}\left(\Delta \mathrm{E}_{\text {pico }}=115 \mathrm{mV}\right)$. A modificação proporcionou uma resposta mais eletrocatalítica com um deslocamento de $43 \mathrm{mV}$ para valores menos positivos do potencial de oxidação do $\mathrm{Fe}(\mathrm{CN})_{6}{ }^{3-}$. A oxidação no eletrodo de $\mathrm{Au} / \mathrm{ssDNA}$ /SWCNTs ocorre em +417 mV e no eletrodo de $\mathrm{Au}$ em $+460 \mathrm{mV}$. Mostrando que a modificação da superfície do ouro melhora a reversibilidade do sistema.

Foram observados também significativos aumentos nas correntes de pico anódicas $\left(\mathrm{I}_{\mathrm{pa}}\right)$ e catódicas $\left(\mathrm{I}_{\mathrm{pc}}\right)$. O eletrodo de Au/ssDNA/SWCNT funcionalizado apresentou um aumento de $280 \%$ na $\mathrm{I}_{\mathrm{pa}}$ em relação ao eletrodo de Au. A partir dos estudos de voltametria cíclica, utilizando um par redox com comportamento bem estabelecido, foi possível evidenciar que a etapa de modificação da superfície do eletrodo de $\mathrm{Au}$ com o hibrido ssDNA/SWCNT melhorou o caráter eletrocatalítico e condutor do eletrodo. Estas características foram observadas devido à melhoria da reversibilidade do sistema, ao deslocamento do potencial de oxidação para valores mais negativos e aos significativos aumentos nas correntes de oxidação e redução.

O comportamento eletrocatalítico do hibrido sobre a superfície do Au foi observado com um estudo de espectroscopia de impedância eletroquímica (EIS). Com os experimentos 
de EIS conseguiu-se obter os valores da resistência de transferência de carga, para a reação de oxidação do par redox $\mathrm{Fe}(\mathrm{CN})_{6}{ }^{3-} / \mathrm{Fe}(\mathrm{CN})_{6}{ }^{4-}$, nas superfícies dos eletrodos. Os espectros de EIS foram analisados em potencial de circuito aberto (do inglês open circuite potential OCP). Os espectros de impedância são mostrados na Figura 9, na forma de diagramas de Nyquist, o qual consiste na formação de um semicírculo, em altas e médias frequências relacionada com o controle cinético e uma reta, em baixas frequências, relacionados com o controle difusional da velocidade da reação.

Figura 9 - Diagramas de Nyquist para os eletrodos de Au: (A) Au e (ם) Au/ssDNA/SWCNT na presença de $\mathrm{Na}_{2} \mathrm{SO}_{4} 0,1 \mathrm{~mol} \mathrm{~L}^{-1}$ contendo $\mathrm{Fe}(\mathrm{CN})_{6}{ }^{3-14-} 1,0 \mathrm{mmol} \mathrm{L}^{-1}$. Os espectros foram coletados em potencial de circuito aberto, com frequência vaiando de $100 \mathrm{KHz}$ a $0,1 \mathrm{~Hz}$.

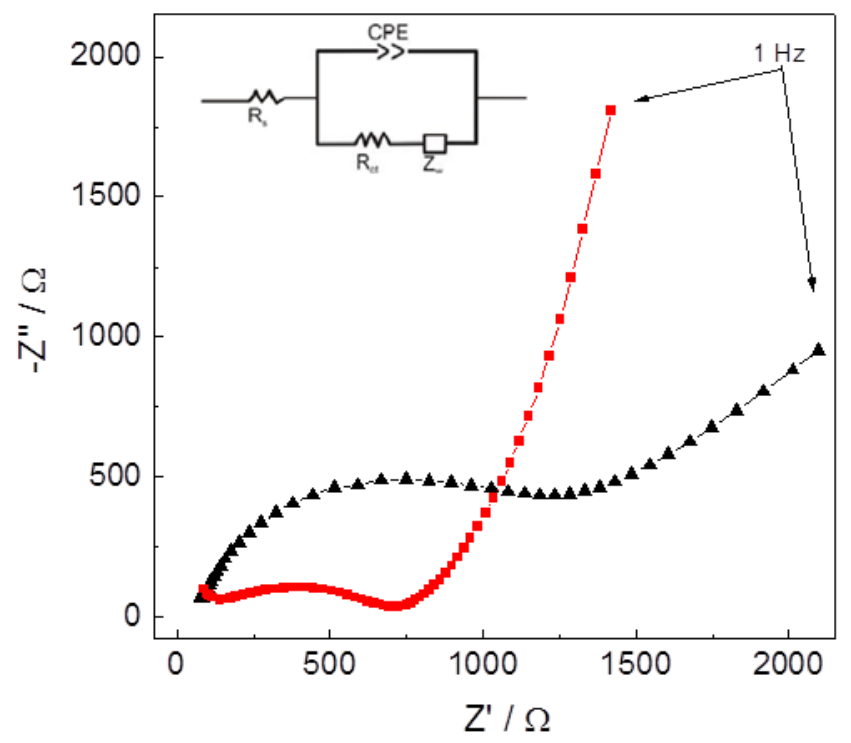

Para análise quantitativa dos resultados de EIS foi utilizado um circuito equivalente de Randles modificado (detalhe da Figura 9), que consiste na resistência da solução $\mathrm{R}_{\mathrm{s}}$, ligada em série com uma combinação em paralelo de um elemento de fase constante CPE (usado para representar um capacitor não ideal) e uma resistência de transferência de carga $R_{c t}$, no qual, esse sistema está ligada em série com uma impedância de Warburg $\mathrm{Z}_{\mathrm{w}}$ (domínio difusional do sistema).

Foi observado, que o eletrodo com o hibrido Au/ssDNA/SWCNT apresentou o menor tamanho de semicírculo, indicando o menor valor de resistência de transferência de carga $\mathrm{R}_{\mathrm{ct}}$. Esta diminuição de $\mathrm{R}_{\mathrm{ct}}$ pode estar ligada a modificação da superfície do eletrodo de $\mathrm{Au}$, a qual age diretamente na velocidade da resposta do analito na superfície do eletrodo. A Tabela 1 dispõe os valores de $R_{c t}$ calculados para todos os sistemas estudados. Estes valores foram obtidos a partir dos ajustes dos espectros, utilizando o programa de simulação Zplot view. 
Tabela 1- Sumário dos parâmetros de EIS estimados para os eletrodos, em $0,1 \mathrm{~mol} \mathrm{~L}^{-1} \mathrm{de}$ $\mathrm{Na}_{2} \mathrm{SO}_{4}$ contendo $1,0 \mathrm{mmol} \mathrm{L}^{-1}$ de $\mathrm{K}_{3} \mathrm{Fe}(\mathrm{CN})_{6}$.

\begin{tabular}{lccc}
\hline Eletrodos & $\mathbf{R}_{\mathbf{s}} / \mathbf{\Omega}$ & $\mathbf{R}_{\mathrm{ct}} / \mathbf{\Omega}$ & $\mathbf{k}_{\mathrm{ap}} / \mathbf{c m ~ s}^{-\mathbf{1}}$ \\
\hline $\mathrm{Au}$ & 56,1 & 1583,2 & $3,36 \times 10^{-5}$ \\
$\mathrm{Au} / \mathrm{ssDNA} / \mathrm{SWCNT}$ & $\mathbf{4 8 , 8}$ & $\mathbf{7 0 3 , 8}$ & $\mathbf{7 . 5 6} \times \mathbf{1 0}^{-\mathbf{5}}$ \\
\hline
\end{tabular}

O termo $k_{a p}$ é a constante aparente de velocidade, que foi calculado a partir da seguinte equação

$$
k_{\mathrm{app}}=\frac{R T}{F^{2} R_{\mathrm{ct}} c}
$$

A partir desta equação temos que c é a concentração $\left(\mathrm{mol} \mathrm{ml}{ }^{-1}\right)$ de $\mathrm{K}_{3} \mathrm{Fe}(\mathrm{CN})_{6}, \mathrm{R}_{\mathrm{ct}}$ é a resistência de transferência de carga $(\Omega), \mathrm{R}$ (constante física dos gases), T (temperatura) e F a constante de Faraday. Como apresentado na Tabela 1, o eletrodo de Au/ssDNA/SWCNT apresentou o maior valor na constante aparente de velocidade, ou seja, as propriedades eletrocatalíticas adquiridas após a modificação, proporcionaram uma diminuição da resistência de transferência de carga, aumentando a velocidade da reação redox. Esse aumento no valor de $\mathrm{k}_{\mathrm{ap}}$ está em concordância com os experimentos de voltametria cíclica, que mostraram que o eletrodo modificado melhora a reversibilidade, aumentando o $I_{p a}$ e $I_{p c}$ e deslocando para valores mais negativos o potencial de oxidação do $\mathrm{Fe}(\mathrm{CN})_{6}{ }^{3-}$.

A fim de confirmar a presença de ssDNA/SWCNTs alinhados verticalmente, um estudo de dessorção da monocamada formada (ssDNA / SWCNT) foi realizado. O processo de dessorção da monocamada é baseado na clivagem da ligação Au-S, em que um átomo de enxofre é derivado molécula de ssDNA, de acordo com o estudo realizado por Kawaguchi et al. ${ }^{69}$. Assim, experimentos de voltametria de onda quadrada, SWV (do inglês square wave voltammetry), foram realizadas utilizando eletrodos de Au liso e Au/ssDNA/SWCNT, com uma frequência de $50 \mathrm{~Hz}$, amplitude de pulso de $100 \mathrm{mV}$ e o potencial de passo de $1 \mathrm{mV}$, em $0,1 \mathrm{~mol} \mathrm{~L}^{-1}$ de $\mathrm{NaOH}$, conforme mostrado na Figura 10. 
Figura 10 - Voltamogramas de SWV em $0.1 \mathrm{~mol} \mathrm{~L}^{-1}$ de $\mathrm{NaOH}$ para: eletrodos $\mathrm{Au}$ sem modificação (linha vermelha) e o eletrodo modificado Au/ssDNA/SWCNT (linha preta).

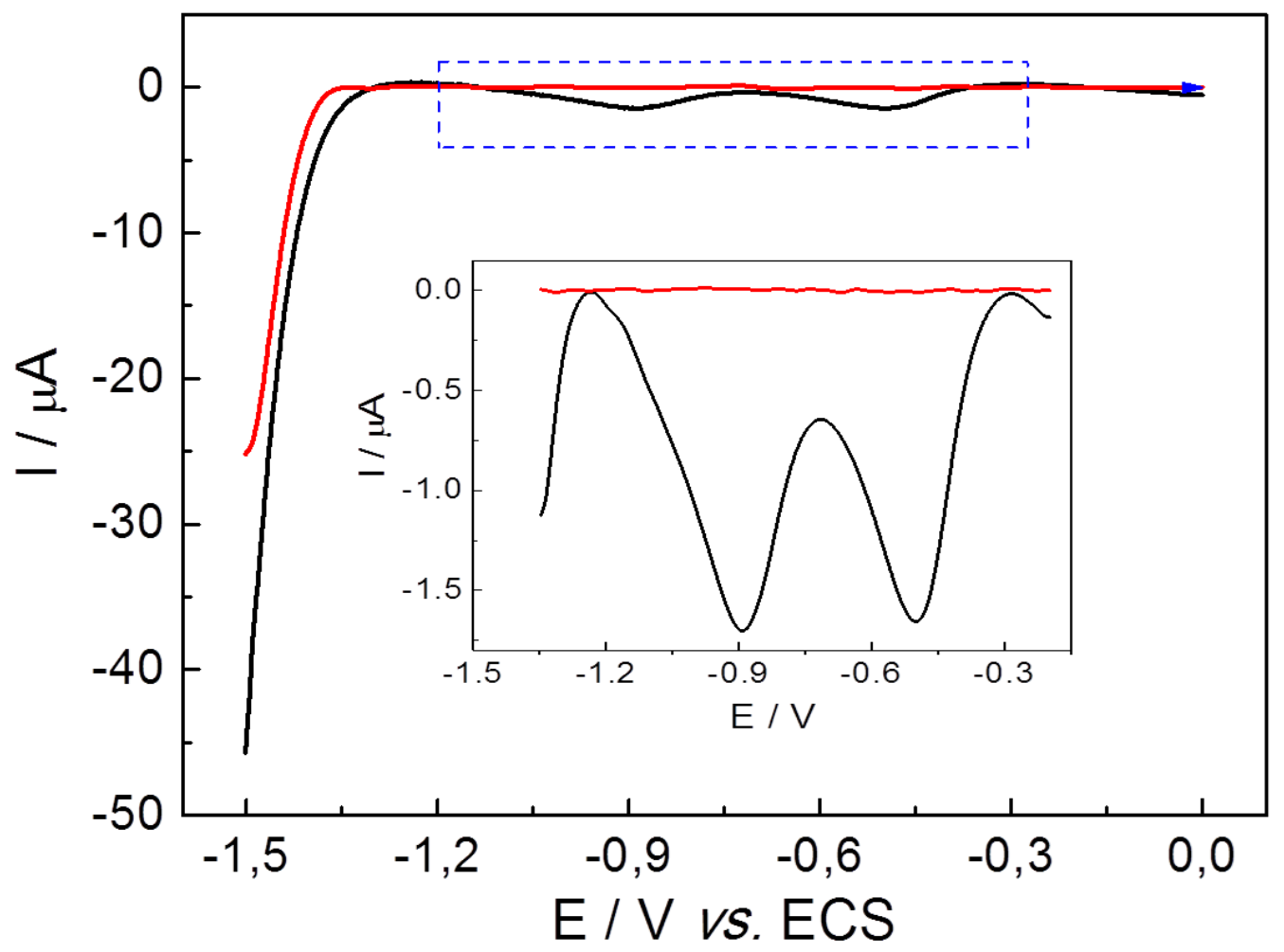

Para o eletrodo de Au não modificado não foi observado qualquer processo de redução na região de potenciais entre $-0,3$ e $-1,2 \mathrm{~V}$ estudada, o que indica que nenhuma espécie de enxofre foi adsorvida na superfície Au. No entanto, para o eletrodo modificado $\mathrm{Au} / \mathrm{ssDNA}$ /SWCNT foram observados dois processos de redução nos potenciais de -500 e de $-880 \mathrm{mV}$. A presença de dois picos de redução é devida à formação de regiões distintas com diferentes formas de organizar monocamada. Cada forma de organização monocamada apresenta uma energia de adsorção característica. Espera-se que o processo de dessorção para diferentes monocamadas apresente diferentes energias que conduzam à dessorção em potenciais diferentes ${ }^{70}$. Assim, este estudo confirmou que a superfície de Au foi modificado com uma monocamada contendo átomos de enxofre, como é o híbrido formado por ssDNA/SWCNT. 


\section{2 - Características eletroquímicas do Bisfenol-A}

\subsubsection{Efeito da modificação do eletrodo com ssDNA / SWCNT na oxidação eletroquímica do Bisfenol-A}

O efeito da modificação da superfície Au com o nanohíbrido ssDNA / SWCNT sobre a resposta da oxidação do BPA foi avaliado em $\mathrm{Na}_{2} \mathrm{SO}_{4} 0,1 \mathrm{~mol} \mathrm{~L}{ }^{-1}, \mathrm{pH} \mathrm{6,0,} \mathrm{contendo} 100$ $\mu$ mol $\mathrm{L}^{-1}$ de BPA. Os experimentos foram realizados usando $\mathrm{CV}$, com uma velocidade de varredura de $50 \mathrm{mV} \mathrm{s}^{-1}$.

O comportamento eletroquímico do BPA na superfície de ssDNA/SWCNT é apresentado na Figura 11, onde o eletrodo de Au/ssDNA/SWCNT (linha azul) exibiu um processo de oxidação com um pico anódico em um valor de potencial de $510 \mathrm{mV}$. Este processo de oxidação está relacionado com a eletro-oxidação de BPA, que gera íons fenoxeno (espécie representada por II), uma espécie de radical fenoxi ${ }^{71}$ que foram gerados e podem interagir com espécies de nucleófilos, como podemos ver na reação abaixo:

Figura 11 - Voltamogramas cíclicos de primeiro ciclo para O Bisfenol: eletrodo de $\mathrm{Au}($ - ) e de Au/DNA/SWCNT ( - ) funcionalizados, com $0,1 \mathrm{~mol} \mathrm{~L}^{-1} \mathrm{Na}_{2} \mathrm{SO}_{4}$ contendo $100 \mu \mathrm{mol} \mathrm{L}^{-1}$ de BPA, a $50 \mathrm{mVs}^{-1}$.

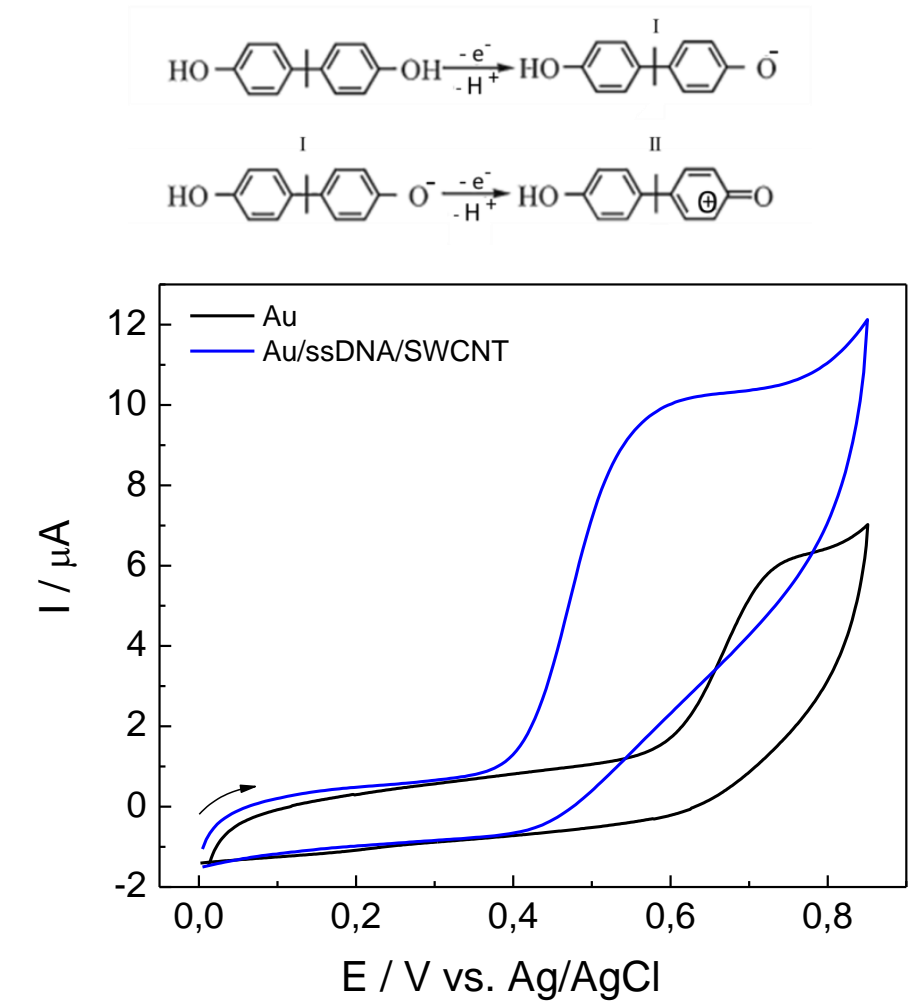


O processo ocorreu em um potencial menos positivo do que o valor observado para o eletrodo de Au não modificado (linha preta), ou seja $720 \mathrm{mV}$. Além disso, o processo oxidativo referente à superfície modificada mostrou-se mais catalítico, proporcionando um aumento no valor da corrente de pico de oxidação de $163 \%$ quando comparada com a superfície não modificada. A mudança no valor do potencial e do aumento da corrente de pico refletem a atividade eletrocatalítica e o aumento da área de superfície eletroativa pelo híbrido formado (ssDNA/SWCNT), respectivamente. Outro fator observado na eletro-oxidação de BPA é o potencial de onset (potencial onde a resposta de corrente começa). $\mathrm{O}$ eletrodo não modificado apresentou um potencial de onset de $560 \mathrm{mV}$, após a modificação, o efeito eletroativo do híbrido sobre a superfície desloca o potencial para $352 \mathrm{mV}$, uma variação de $208 \mathrm{mV}$ para valores de potencial menos positivo.

\subsubsection{Estudos da adsorção do Bisfenol-A}

Experimentos de EIS foram realizados para investigar a possibilidade de adsorção da BPA na superfície do eletrodo. Os espectros de impedância foram registrados utilizando OCP em três situações diferentes: (a) $0,1 \mathrm{~mol} \mathrm{~L}^{-1}$ de $\mathrm{Na}_{2} \mathrm{SO}_{4}$ (pH 6,0) (solução em branco), (b) 0,1 mol L ${ }^{-1}$ de $\mathrm{Na}_{2} \mathrm{SO}_{4}$ (pH 6,0) contendo $100 \mu \mathrm{mol} \mathrm{L}^{-1}$ de BPA, e (c) $0,1 \mathrm{~mol} \mathrm{~L}^{-1} \mathrm{de} \mathrm{Na}_{2} \mathrm{SO}_{4}$ (pH 6,0) após 10 voltamogramas cíclicos sucessivos entre 0,1 e 1,0 V vs Ag/AgCl em uma solução contendo $100 \mu \mathrm{mol} \mathrm{L}^{-1}$ de BPA.

Na Figura 12, os espectros de impedância são apresentados como gráficos de plano complexo para o eletrodo de Au/ssDNA/SWCNT. Um circuito elétrico equivalente de uma resistência da célula, $\mathrm{R}_{\Omega}$, em série com a combinação em paralelo de um elemento de fase constante, CPE, e uma resistência de transferência de carga, $\mathrm{R}_{\mathrm{ct}}$, foi usado para ajustar os espectros. O CPE foi considerado necessário devido à natureza heterogênea da superfície do eletrodo, expressa através do expoente $\alpha$, onde $\alpha=1$ representa uma superfície perfeitamente lisa e uniforme. $\mathrm{Em} \mathrm{Na}_{2} \mathrm{SO}_{4}$, o declive da linha reta pode ser considerado como um capacitor não-ideal, que é uma característica de dupla camada de carga sobre uma superfície não homogénea, neste caso $\mathrm{R}_{\mathrm{ct}}$ foi obtida pelo circuito de ajuste. Os valores calculados para CPE e $\alpha$ foram de $1,35 \mu \mathrm{Fs} \mathrm{s}^{\alpha-1}$ e 0,87 , respectivamente. 
Figura 12 - Diagramas de Nyquist para o eletrodo de Au/ssDNA/SWCNT em: ( $\boldsymbol{\Delta}) \mathrm{Na}_{2} \mathrm{SO}_{4}$ $0,1 \mathrm{~mol} \mathrm{~L}^{-1},(\boldsymbol{\square}) \mathrm{Na}_{2} \mathrm{SO}_{4} 0,1 \mathrm{~mol} \mathrm{~L}{ }^{-1}$ contendo BPA $0,1 \mathrm{mmol} \mathrm{L}^{-1}$ e $(\bigcirc) \mathrm{Na}_{2} \mathrm{SO}_{4} 0,1 \mathrm{~mol} \mathrm{~L}^{-1}$ depois de 10 ciclos voltamétricos na solução de BPA.

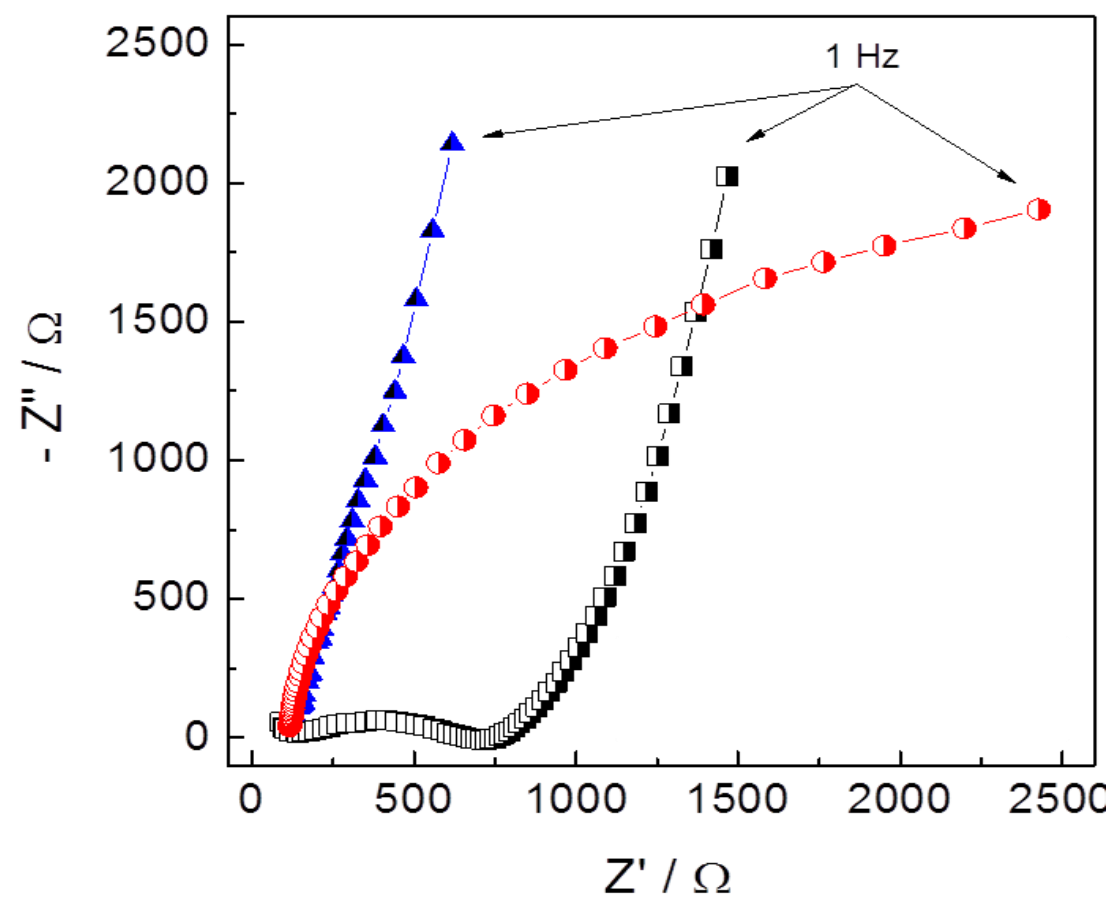

Com a adição de $100 \mu \mathrm{mol} \mathrm{L} \mathrm{L}^{-1}$ de BPA no eletrólito, o espectro apresentou um semicírculo na região de altas frequências, característica de uma reação de transferência de carga, e uma linha reta em baixas frequências, correspondentes ao controle difusional da reação. Os valores calculados pela análise do sistema foram $0,745 \mathrm{k} \Omega$ para $\mathrm{R}_{\mathrm{ct}}, 4,82 \mu \mathrm{F} \mathrm{s}^{\alpha-1}$ para CPE e 0,85 para $\alpha$.

Após dez ciclos, com a voltametria cíclica, na presença de BPA, um espectro de impedância do eletrodo de $\mathrm{Au} / \mathrm{ssDNA} / \mathrm{SWCNT}$ foi medido em $\mathrm{Na}_{2} \mathrm{SO}_{4}$ sem BPA. Foram observadas diferenças significativas nos espectros após a exposição do eletrodo à solução de BPA. Os valores calculados foram $4,20 \mu \mathrm{F} \mathrm{s}^{\alpha-1}$ para CPE, 0,83 para $\alpha$ e 3,65 $\mathrm{k} \Omega$ para $\mathrm{R}_{\mathrm{ct} .} \mathrm{O}$ aumento nos valores de $\mathrm{CPE}$ e $\mathrm{R}_{\mathrm{ct}}$ pode ser atribuído à saturação dos sítios ativos disponíveis na superfície do eletrodo por moléculas de BPA, confirmando assim o processo de adsorção que ocorre a medida que o BPA é oxidado. 


\subsubsection{Estudos de otimização de Bisfenol-A no eletrodo Au/ssDNA/SWCNT}

Com a finalidade de maximizar o sinal analítico da técnica de voltametria de pulso diferencial, DPV (do inglês differential pulse voltammetry) e melhorar as condições experimentais, a resposta para o eletrodo de Au/ssDNA/SWCNT foi estudada em relação ao $\mathrm{pH}$, salto de potenciais e a amplitude de pulso. Essas medidas foram realizadas em solução de $\mathrm{Na}_{2} \mathrm{SO}_{4}$ 0,1 mol L${ }^{-1}$ (pH 6,0) contendo BPA $100 \mu \mathrm{mol} \mathrm{L}{ }^{-1}$. A Tabela 2 descreve o intervalo estudado para cada variável e as melhores condições encontradas.

Tabela 2. Otimizações dos parâmetros da técnica de DPV para a oxidação de BPA no eletrodo de Au/ssDNA/SWCNT

\begin{tabular}{ccc}
\hline & Valores estudados & Valor Otimizados \\
\hline $\mathrm{pH}$ & $3,0-9,0$ & 6,0 \\
Amplitude $(\mathrm{mV})$ & $10-100$ & 50 \\
Salto de potencial $(\mathrm{mV})$ & $1-10$ & 2 \\
\hline
\end{tabular}

O efeito do $\mathrm{pH}$ sobre o potencial de pico $\left(\mathrm{E}_{\mathrm{pa}}\right)$ e da corrente de pico $\left(\mathrm{I}_{\mathrm{pa}}\right)$ de oxidação do BPA foi examinado em $\mathrm{Na}_{2} \mathrm{SO}_{4}$ 0,1 mol L ${ }^{-1}$ contendo $100 \mu \mathrm{mol} \mathrm{L}^{-1}$ de BPA, com o $\mathrm{pH}$ variando entre 3,0 e 9,0, utilizando o eletrodo de Au/ssDNA/SWCNT, como mostrado na Figura 13. 
Figura 13 - Gráfico A representa a relação 3D entre o pH, a Epa e a Ipa. O gráfico B mostra a relação linear entre a variação de $\mathrm{pH}$ vs. $\mathrm{E}_{\mathrm{pa}}(\boldsymbol{\square})$ e $\mathrm{pH}$ vs. $\mathrm{I}_{\mathrm{pa}}(\boldsymbol{\square})$, em um meio $0,2 \mathrm{~mol} \mathrm{~L}^{-1}$ PBS contendo $1,0 \mathrm{mmol} \mathrm{L}{ }^{-1}$ de BPA.
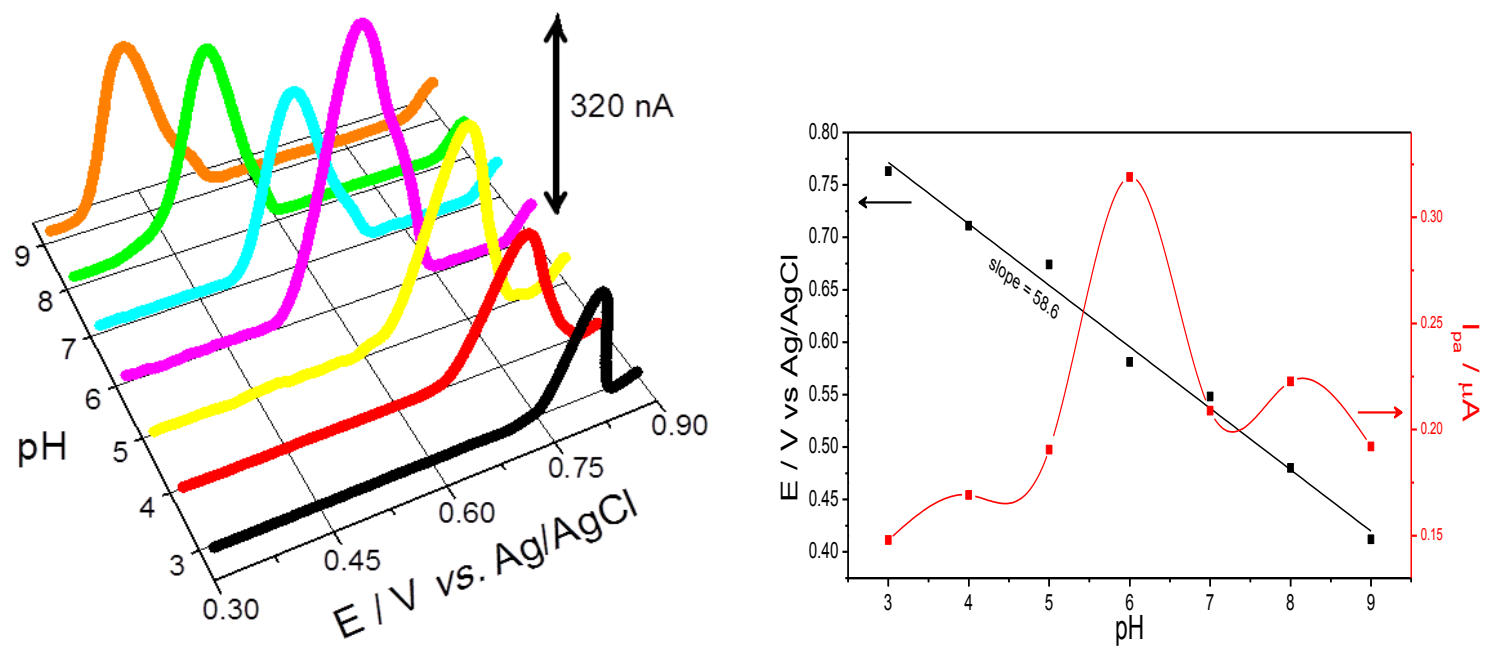

Podemos ver na Figura 13 que o aumento nos valores do $\mathrm{pH}$ promoveu uma mudança no $E_{p a}$ para valores menos positivos, em uma relação linear, cuja inclinação da reta é, aproximadamente, $58,9 \mathrm{mV} \mathrm{dec}{ }^{-1}$. Assim, a oxidação do BPA é dependente da concentração hidrogeniônica e envolve uma etapa de protonação, com número igual de prótons e elétrons envolvidos na oxidação, mesmo nestes valores de $\mathrm{pH}$. A dependência de $\mathrm{pH} v s$. $\mathrm{I}_{\mathrm{pa}}$ mostrou que o pico de corrente tem um valor máximo em $\mathrm{pH}$ 6,0 diminuindo para valores maiores e para valores menores de $\mathrm{pH}$. Após a análise desses experimentos, todas as análises posteriores com o eletrodo de $\mathrm{Au} / \mathrm{ssDNA} / \mathrm{SWCNT}$ foram realizados em $\mathrm{pH}$ 6,0.

Outros parâmetros como amplitude de potencial e salto de potencial foram estudados, sob as condições experimentais apresentadas anteriormente. As medidas de DPV foram realizadas variando a amplitudes na faixa de 10 a $100 \mathrm{mV}$ e a melhor resposta para a amplitude no processo de oxidação do BPA foi de $50 \mathrm{mV}$. Finalmente, o salto de potencial foi variado em um intervalo de $1-10 \mathrm{mV}$ e acima de $2 \mathrm{mV}$ não foi observada qualquer influencia na variação da corrente de pico. Desta forma o valor de salto de potencial de $2 \mathrm{mV}$ foi escolhido.

\subsubsection{Características analíticas para o BPA}

Utilizando as condições optimizadas para DPV conforme descrito no item 4.2.1, o eletrodo proposto $\mathrm{Au} / \mathrm{ssDNA} / \mathrm{SWCNT}$ foi aplicado para investigar a resposta eletroquímica com relação a concentração de BPA. Todas as medidas foram feitas em triplicata em uma 
solução de $\mathrm{Na}_{2} \mathrm{SO}_{4}$ 0,1 mol L'-1 pH 6,0 e os resultados são indicados como o valor médio na Figura 14.

A resposta analítica mostrada na Figura 14 tem um comportamento linear na faixa entre $1,0-4,5 \mu \mathrm{mol} \mathrm{L}{ }^{-1}$, de acordo com a seguinte equação:

$$
I(\mu \mathrm{A})=0.019(\mu \mathrm{A})+5.82\left(\mu \mathrm{A} / \mu \mathrm{molL}^{-1}\right)[\mathrm{BPA}]
$$

Figura 14 - Curva analítica utilizando DPV com o eletrodo de Au/ssDNA/SWCNT com os parâmetros otimizados para as seguintes concentrações de BPA em $\mu \mathrm{mol} \mathrm{L} \mathrm{L}^{-1}$ : (a) 1,00; (b) 1,50; (c) 2,00; (d) 2,50; (e) 3,00; (f) 3,50; (g) 4,00 e (h) 4,50. Detalhe: dependência linear do pico de corrente com a concentração de BPA

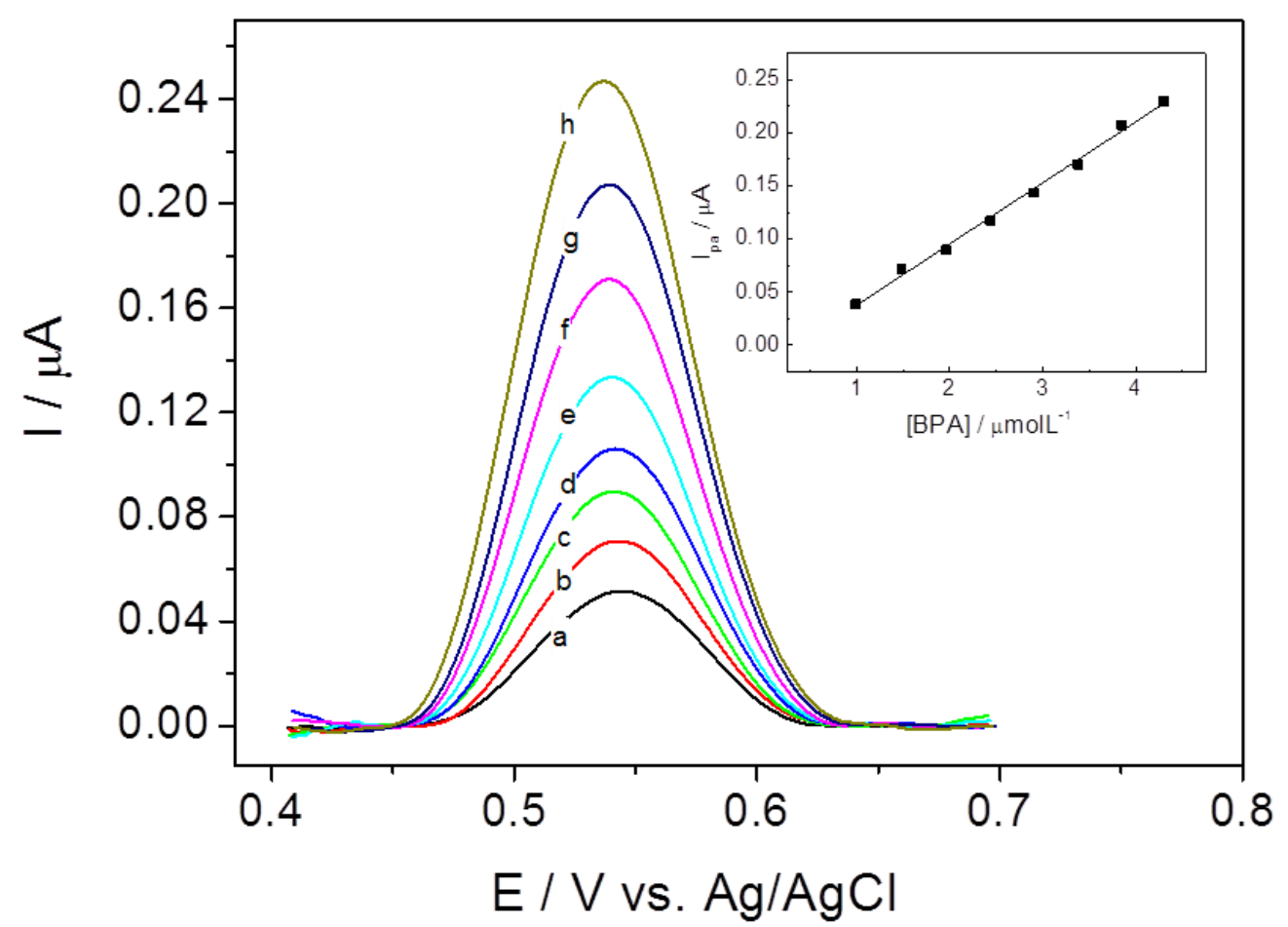

Obtendo um coeficiente de correlação de 0,996 ( $\mathrm{n}=10)$. O limite de detecção (LOD) de $11,0 \mathrm{nmol} \mathrm{L}^{-1}\left(2,51 \mu \mathrm{g} \mathrm{L}^{-1}\right)$ foi determinada utilizando a relação de $3 \sigma / \mathrm{s}$, onde s é a inclinação da reta obtida na curva de calibração, onde $\sigma$ é o desvio padrão do valor médio para 10 voltamogramas do branco, determinada de acordo com as recomendações da IUPAC $^{72}$. O valor obtido é da ordem daquele obtido por Niu et al. ${ }^{73}$ utilizando eletrodos de carbono vítreo modificados com grafeno e nanopartículas de ouro, ou seja 35,0 nM, obtido por voltametria linear em tampão fosfato $0,1 \mathrm{M}$, um pouco superior aquele obtido por Gao et al. ${ }^{74}$ com o eletrodo de carbono vítreo modificado com uma mistura de nanotubos de carbono de parede simples e $\beta$-ciclodextrina em tampão fosfato $0,1 \mathrm{M}$, por voltametria cíclica mostrou 
um limite de detecção de 1,0 nM, ou ainda da ordem daquele publicado por Yin et al. ${ }^{75}, 10$

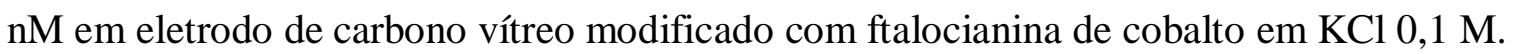

\section{CONCLUSÕES}

Após leitura e análise dos resultados apresentados na seção anterior, elaborou-se uma conclusão do desenvolvimento, caracterização e aplicação dos eletrodos de ouro modificados com DNA e nanotubos de carbono para estudo de interferentes endócrinos.

A etapa de modificação dos CNTs com o ssDNA e imobilização sobre os eletrodos de ouro mostrou-se imprescindível, para as propriedades eletrocatalíticas dos interferentes endócrinos estudados.

A analise morfológica realizada com AFM demostraram que a etapa de modificação foi realizada com êxito, uma vez que a rugosidade do sistema teve um aumento de 1,95 nm para o ouro liso para 47,5 $\mathrm{nm}$ após a modificação. E a superfície do eletrodo ao final do processo de modificação apresenta um aumento da área de contato, privilegiando reações na superfície do dispositivo.

Através da caracterização voltamétrica, foi possível observar que a modificação diminuiu os potenciais de oxidação, aumentam as correntes de pico anódicas e catódicas e melhoram a reversibilidade do par redox $\left[\mathrm{Fe}(\mathrm{CN})_{6}\right]^{3-} /\left[\mathrm{Fe}(\mathrm{CN})_{6}\right]^{4-}$, evidenciando o efeito eletrocatalítico dos CNTs funcionalizados com ssDNA.

O efeito eletrocatalítico foi confirmado por experimentos de espectroscopia de impedância eletroquímica, na qual foi evidenciado que os eletrodos construídos com o nanohibrido funcionalizados diminuíram a resistência de transferência eletrônica e consequentemente, aumentaram a constante aparente de velocidade da reação redox.

Os sensores eletroquímicos modificados mostraram-se eficientes na determinação de Bisfenol-A, pois obteve-se uma acréscimo nas respostas eletroquímicas e um alto poder mediador.

A utilização de sensores baseados em filmes de ssDNA/CNT, conseguiu para o Bisfenol-A melhorar a resposta, aumentando o pico de oxidação e melhorando as constantes estudadas com a espectroscopia de impedância. Com a curva de calibração foi possível 
encontrar a região de concentração com resposta linear e determinar a sensibilidade para o sistema estudado.

O sensor compósito $\mathrm{Au} / \mathrm{ssDNA} / \mathrm{CNT}$ mostrou-se robusto, de fácil preparação, seletivo e altamente sensível na determinação de Bisfenol-A em condições de laboratório, sem que houvesse alguma interferência, além das amostras não necessitarem de qualquer etapa de prétratamento, sendo comparada a HPLC e apresentando valores siginificativamente igual segundo o teste $\mathrm{t}$ com $95 \%$ de certeza. A utilização de sensores modificados com ssDNA/CNT apresenta-se como uma metodologia sensível, e serve como uma alternativa aos métodos oficiais de análise. 


\section{REFERÊNCIAS BIBLIOGRÁFICAS}

1.IIJIMA, S. HELICAL MICROTUBULES OF GRAPHITIC CARBON. Nature, v. 354, n. 6348, 56-58, 1991.

2.VILATELA, J. J.; KHARE, R.; WINDLE, A. H. The hierarchical structure and properties of multifunctional carbon nanotube fibre composites. Carbon, v. 50, n. 3, 1227-1234, 2012.

3.CIPOLLONE, S. Carbon Nanotubes and Neurons: Nanotechnology Application to the Nervous System. . Dottoranda:, UNIVERSITA’ DEGLI STUDI DI TRIESTE, 2009.

4.CHEN, J. L.; CHEN, Q. H.; MA, Q. Influence of surface functionalization via chemical oxidation on the properties of carbon nanotubes. J. Colloid Interface Sci., v. 370, n., 32-38, 2012.

5.YELLAMPALLI, S.; CARBON NANOTUBES - SYNTHESIS, CHARACTERIZATION, APPLICATIONS. july, 2011 ed.; InTech 2011 Vol. n.1.

6.MORAES, F. C.; Nanotubos de carbono no desenvolvimento de sensores eletroquímicos. Tese de Doutorado, Universidade de São Carlos, 2010.

7.BAUGHMAN, R. H.; ZAKHIDOV, A. A.; DE HEER, W. A. Carbon nanotubes - the route toward applications. Science, v. 297, n. 5582, 787-792, 2002.

8.MASHETER, A. T.; ABIMAN, P.; WILDGOOSE, G. G.; WONG, E.; XIAO, L.; REES, N. V.; TAYLOR, R.; ATTARD, G. A.; BARON, R.; CROSSLEY, A.; JONES, J. H.; COMPTON, R. G. Investigating the reactive sites and the anomalously large changes in surface $\mathrm{pK}(\mathrm{a})$ values of chemically modified carbon nanotubes of different morphologies. J. Mater. Chem., v. 17, n. 25, 2616-2626, 2007.

9.HIURA, H.; EBBESEN, T. W.; TANIGAKI, K.; Opening and purification of carbon nanotubes in high yields. adv. mater., v. 7, n. 3, 275-276, 1995.

10.LAKSHMI, N.; RAJALAKSHMI, N.; DHATHATHREYAN, K. S.; Functionalization of various carbons for proton exchange membrane fuel cell electrodes: analysis and characterization. J. Phys. D-Appl. Phys., v. 39, n. 13, 2785-2790, 2006.

11.PARTHASARATHY, R.; LIN, X. M.; JAEGER, H. M.; Electronic transport in metal nanocrystal arrays: The effect of structural disorder on scaling behavior. Phys. Rev. Lett., v. 87, n. 18, 2001. 
12.CHOU, A.; BOCKING, T.; LIU, R.; SINGH, N. K.; MORAN, G.; GOODING, J. J. Effect of dialysis on the electrochemical properties of acid-oxidized single-walled carbon nanotubes. J. Phys. Chem. C, v. 112, n. 36, 14131-14138, 2008.

13.PILLAI, S. K.; RAY, S. S.; MOODLEY, M. Purification of single-walled carbon nanotubes. J. Nanosci. Nanotechnol., v. 7, n. 9, 3011-3047, 2007.

14.MORAES, F. C.; CABRAL, M. F.; MASCARO, L. H.; MACHADO, S. A. S. The electrochemical effect of acid functionalisation of carbon nanotubes to be used in sensors development. Surf. Sci., v. 605, n. 3-4, 435-440, 2011.

15.COELHO, D.; Caracterização eletroquímica de uma monocamada auto montada mista composta por ácido 3-mercaptopropiônico e ácido 11-mercaptoundecanóico. Mestrado, Universidade de São Paulo, São Carlos, 2011.

16.LAN, G. H.; LIU, Y. X.; ZENG, X. D.; LIU, Y.; WEI, W. Z.; Carbon nanotubes on low resistance monolayer-modified glassy carbon electrode as chemo/biosensor. Journal of Electroanalytical Chemistry, v. 634, n. 2, 98-103, 2009.

17.VISWANATHAN, S.; RANI, C.; VIJAY ANAND, A.; HO, J.-A. A.; Disposable electrochemical immunosensor for carcinoembryonic antigen using ferrocene liposomes and MWCNT screen-printed electrode. Biosensors and Bioelectronics, v. 24, n. 7, 1984-1989, 2009.

18.HU, C. G.; ZHANG, Y. Y.; BAO, G.; ZHANG, Y. L.; LIU, M. L.; WANG, Z. L. DNA functionalized single-walled carbon nanotubes for electrochemical detection. Journal of Physical Chemistry B, v. 109, n. 43, 20072-20076, 2005.

19.ZHANG, X.; JIAO, K.; LIU, S.; HU, Y.; Readily Reusable Electrochemical DNA Hybridization Biosensor Based on the Interaction of DNA with Single-Walled Carbon Nanotubes. Analytical Chemistry, v. 81, n. 15, 6006-6012, 2009.

20.VISWANATHAN, S.; RADECKA, H.; RADECKI, J.; Electrochemical biosensor for pesticides based on acetylcholinesterase immobilized on polyaniline deposited on vertically assembled carbon nanotubes wrapped with ssDNA. Biosensors and Bioelectronics, v. 24, n. 9, 2772-2777, 2009.

21.GULDI, D. M. M., N.; Carbon Nanotubes and Related Structures Synthesis, Characterization, Functionalization, and Applications. WILEY-VCH Verlag GmbH \& Co. KGaA,Weinheim: 2010. p. 
22.HU, C.; ZHANG, Y.; BAO, G.; LIU, M.; WANG, Z. L.; DNA functionalized singlewalled carbon nanotubes for electrochemical detection. Journal of Physical Chemistry B, v. 109, n. 43, 20072-20076, 2005.

23.SÁNCHEZ-POMALES, G.; CABRERA, C. R.;; Vertical attachment of DNA-CNT hybrids on gold. Journal of Electroanalytical Chemistry, v. 606, n. 1, 47-54, 2007.

24.MCLEAN, R. S.; HUANG, X. Y.; KHRIPIN, C.; JAGOTA, A.; ZHENG, M. Controlled two-dimensional pattern of spontaneously aligned carbon nanotubes. Nano Letters, v. 6, n. 1, 55-60, 2006.

25.GOODING, J. J.; WIBOWO, R.; LIU, J. Q.; YANG, W. R.; LOSIC, D.; ORBONS, S.; MEARNS, F. J.; SHAPTER, J. G.; HIBBERT, D. B.; Protein electrochemistry using aligned carbon nanotube arrays. Journal of the American Chemical Society, v. 125, n. 30, 9006-9007, 2003.

26.PLANK, N. O. V.; CHEUNG, R.; ANDREWS, R. J.; Thiolation of single-wall carbon nanotubes and their self-assembly. Applied Physics Letters, v. 85, n. 15, 3229-3231, 2004.

27.ZHENG, M.; JAGOTA, A.; SEMKE, E. D.; DINER, B. A.; MCLEAN, R. S.; LUSTIG, S. R.; RICHARDSON, R. E.; TASSI, N. G.; DNA-assisted dispersion and separation of carbon nanotubes. Nature Materials, v. 2, n. 5, 338-342, 2003.

28.DWYER, C.; GUTHOLD, M.; FALVO, M.; WASHBURN, S.; SUPERFINE, R.; ERIE, D.; DNA-functionalized single-walled carbon nanotubes. Nanotechnology, v. 13, n. 5, 601604, 2002.

29.KERMAN, K.; MORITA, Y.; TAKAMURA, Y.; OZSOZ, M.; TAMIYA, E.; DNAdirected attachment of carbon nanotubes for enhanced label-free electrochemical detection of DNA hybridization. Electroanalysis, v. 16, n. 20, 1667-1672, 2004.

30.GUISEPPI-ELIE, A.; RAHMAN, A. R. A.; SHUKLA, N. K.; SAM-modified microdisc electrode arrays (MDEAs) with functionalized carbon nanotubes. Electrochimica Acta, v. 55, n. 14, 4247-4255, 2010.

31.BILA, D. M. A. D., MÁRCIA.; Desreguladores endócrinos no meio ambiente: efeitos e conseqüências. Química Nova, v. 30, n. 3, 651-666, 2007.

32.GHISELLI, G.; JARDIM, W. F.; Interferentes endócrinos no ambiente. Química Nova, v. 30, n., 695-706, 2007. 
33.BRUGNERA, M. F.; Eletroanálise e oxidação fotoeletrocatalítica dos disruptores endócrinos bisfenol A e nonilfenol sobre eletrodos de nanotubos de Ti/TiO2 auto-organizados Universidade Estadual Paulista "Júlio de Mesquita Filho" 2009.

34.BIRKETT, J. W. L., J.N.; Endocrine Disrupters in Wastewater and Sludge Treatment Processes. United States: IWA Publishing, 2003. p.

35.LINTELMANN, J.; KATAYAMA, A.; KURIHARA, N.; SHORE, L.; WENZEL, A.; Endocrine disruptors in the environment - (IUPAC Technical Report). Pure and Applied Chemistry, v. 75, n. 5, 631-681, 2003. 36.apud ref. 3. ed.; Commission, E., Ed. 1996.

37.COMMUNITIES, C.-C. O. T. E., Community strategy for endocrine disrupters a range of substances suspected of interfering with the hormone systems of humans and wildlife. in communication from the commission to the council and the european parliament, com: brussels, 1999; vol. 17, p 31.

38.GUILlETTE, L. J.; GROSS, T. S.; MASSON, G. R.; MATTER, J. M.; PERCIVAL, H. F.; WOODWARD, A. R.; Developmental abnormalities of the gonad and abnormal sexhormone concentrations in juvenile alligators from contaminated and control lakes in florida. environmental health perspectives, v. 102, n. 8, 680-688, 1994.

39.SODRÉ, F. F. M. C. C. L., M. A. F. ; JARDIM, W. F.; Ocorrência de Interferentes Endócrinos e Produtos Farmacêuticos em Águas Superficiais da Região de Campinas (SP, Brasil). J. Braz. Soc. Ecotoxicol, v. 2, n. 2, 187, 2007.

40.POORAHONG, S.; THAMMAKHET, C.; THAVARUNGKUL, P.; LIMBUT, W.; NUMNUAM, A.; KANATHARANA, P.; Amperometric sensor for detection of bisphenol A using a pencil graphite electrode modified with polyaniline nanorods and multiwalled carbon nanotubes. Microchimica Acta, v. 176, n. 1-2, 91-99, 2012.

41.BESERRA, M. R. S. J. A. R., W. C.; PEREIRA, C. S. S.; O Bisfenol A: Sua Utilização e a Atual Polêmica em Relação aos Possíveis Danos à Saúde Humana. Revista Eletrônica TECCEN, v. v. 5, n. n. 1, p. 37-46, 2012.

42.BRUGNERA, M. F.; GONCALVES TRINDADE, M. A.; BOLDRIN ZANONI, M. V.; Detection of bisphenol a on a screen-printed carbon electrode in ctab micellar medium. analytical letters, v. 43, n. 18, 2823-2836, 2010.

43.RAIMUNDO, C. C. M.; Ocorrência de interferentes endócrinos e produtos farmacêuticos nas águas superficiais da bacia do rio Atibaia. Universidade Estadual de Campinas Instituto de Química 2007. 
44.EUROPE, P.; Applications of Bisphenol A. PC/BPA-group PlasticsEurope, Applications of BPA: 2007.

45.DODDS, E. C. L., W.; Synthetic strogenic Agents without the Phenanthrene Nucleus. Nature, v. 137, n., 996, 1936.

46.FELDMAN, D. T., L. G.; STATHIS, P. A.; MILLER, S. C.; KURZ, W.; HARVEY, D. Identification of $17 \beta$-estradiol as the estrogenic substance in Saccharomyces cerevisiae. Proceedings of the National Academy of Sciences of the United States of America-Biological Sciences, v. 81, n. 15, 4722, 1984.

47.KRISHNAN, A. V.; STATHIS, P.; PERMUTH, S. F.; TOKES, L.; FELDMAN, D. BISPHENOL-A - an estrogenic substance is released from polycarbonate flasks during autoclaving. endocrinology, v. 132, n. 6, 2279-2286, 1993.

48.BILA, D. M.; DEZOTTI, M.; Fármacos no meio ambiente. Química Nova, v. 26, n., 523 $530,2003$.

49.BALlESTEROS, O.; ZAFRA, A.; NAVALON, A.; VILCHEZ, J. L.; Sensitive gas chromatographic-mass spectrometric method for the determination of phthalate esters, alkylphenols, bisphenol $\mathrm{A}$ and their chlorinated derivatives in wastewater samples. Journal of Chromatography A, v. 1121, n. 2, 154-162, 2006.

50.GATIDOU, G.; THOMAIDIS, N. S.; STASINAKIS, A. S.; LEKKAS, T. D.; Simultaneous determination of the endocrine disrupting compounds nonylphenol, nonylphenol ethoxylates, triclosan and bisphenol A in wastewater and sewage sludge by gas chromatography-mass spectrometry. Journal of Chromatography A, v. 1138, n. 1-2, 32-41, 2007.

51.BILES, J. E.; MCNEAL, T. P.; BEGLEY, T. H.; Determination of bisphenol a migrating from epoxy can coatings to infant formula liquid concentrates. Journal of Agricultural and Food Chemistry, v. 45, n. 12, 4697-4700, 1997.

52.LIU, R.; ZHOU, J. L.; WILDING, A.; Simultaneous determination of endocrine disrupting phenolic compounds and steroids in water by solid-phase extraction-gas chromatographymass spectrometry. Journal of Chromatography A, v. 1022, n. 1-2, 179-189, 2004.

53.HERNANDO, M. D.; MEZCUA, M.; GOMEZ, M. J.; MALATO, O.; AGUERA, A.; FERNANDEZ-ALBA, A. R.; Comparative study of analytical methods involving gas chromatography-mass spectrometry after derivatization and gas chromatography-tandem mass spectrometry for the determination of selected endocrine disrupting compounds in wastewaters. Journal of Chromatography A, v. 1047, n. 1, 129-135, 2004. 
54.LEE, H. B.; PEART, T. E.; SVOBODA, M. L.; Determination of endocrine-disrupting phenols, acidic pharmaceuticals, and personal-care products in sewage by solid-phase extraction and gas chromatography-mass spectrometry. Journal of Chromatography A, v. 1094, n. 1-2, 122-129, 2005.

55.MARAGOU, N. C.; LAMPI, E. N.; THOMAIDIS, N. S.; KOUPPARIS, M. A.; Determination of bisphenol $\mathrm{A}$ in milk by solid phase extraction and liquid chromatographymass spectrometry. Journal of Chromatography A, v. 1129, n. 2, 165-173, 2006.

56.LAFLEUR, A. D.; SCHUG, K. A.; A review of separation methods for the determination of estrogens and plastics-derived estrogen mimics from aqueous systems. Analytica Chimica Acta, v. 696, n. 1-2, 6-26, 2011.

57.OUCHI, K.; WATANABE, S.; Measurement of bisphenol A in human urine using liquid chromatography with multi-channel coulometric electrochemical detection. Journal of Chromatography B-Analytical Technologies in the Biomedical and Life Sciences, v. 780, n. 2, 365-370, 2002.

58.PODLIPNA, D.; CICHNA-MARKL, M.; Determination of bisphenol A in canned fish by sol-gel immunoaffinity chromatography, HPLC and fluorescence detection. European Food Research and Technology, v. 224, n. 5, 629-634, 2007.

59.LOOS, R.; HANKE, G.; UMLAUF, G.; EISENREICH, S. J.; LC-MS-MS analysis and occurrence of octyl- and nonylphenol, their ethoxylates and their carboxylates in Belgian and Italian textile industry, waste water treatment plant effluents and surface waters. Chemosphere, v. 66, n. 4, 690-699, 2007.

60.SHAO, B.; HAN, H.; TU, X.; HUANG, L.; Analysis of alkylphenol and bisphenol A in eggs and milk by matrix solid phase dispersion extraction and liquid chromatography with tandem mass spectrometry. Journal of Chromatography B-Analytical Technologies in the Biomedical and Life Sciences, v. 850, n. 1-2, 412-416, 2007.

61.KURAMITZ, H.; NAKATA, Y.; KAWASAKI, M.; TANAKA, S.; Electrochemical oxidation of bisphenol A. Application to the removal of bisphenol A using a carbon fiber electrode. Chemosphere, v. 45, n. 1, 37-43, 2001.

62.ANDREESCU, S.; SADIK, O. A.; Correlation of analyte structures with biosensor responses using the detection of phenolic estrogens as a model. Analytical Chemistry, v. 76, n. 3, 552-560, 2004.

63.NOTSU, H.; TATSUMA, T.; FUJISHIMA, A.; Tyrosinase-modified boron-doped diamond electrodes for the determination of phenol derivatives. Journal of Electroanalytical Chemistry, v. 523, n. 1-2, 86-92, 2002. 
64.MITA, D. G.; ATTANASIO, A.; ARDUINI, F.; DIANO, N.; GRANO, V.; BENCIVENGA, U.; ROSSI, S.; AMINE, A.; MOSCONE, D.; Enzymatic determination of BPA by means of tyrosinase immobilized on different carbon carriers. Biosensors \& Bioelectronics, v. 23, n. 1, 60-65, 2007.

65.WU, T.; WANG, W. Y.; JIANG, L. M.; CHU, Q. C.; DELAIRE，J.; YE，J. N.; Determination of natural and synthetic endocrine-disrupting chemicals (EDCs) in sewage based on SPE and MEKC with amperometric detection. Chromatographia, v. 68, n. 5-6, 339$344,2008$.

66.LU, S. F.; FEI, J. J.; HE, Q.; HU, S. S.; Application of glacy electrode coated with multiwall nanotube film for determination of bisphenol A in plastic waste samples. Chemia Analityczna, v. 49, n. 5, 607-617, 2004.

67.RAHMAN, M. A.; SHIDDIKY, M. J. A.; PARK, J.-S.; SHIM, Y.-B.; An impedimetric immunosensor for the label-free detection of bisphenol A. Biosensors \& Bioelectronics, v. 22, n. 11, 2464-2470, 2007.

68.HUANG, W.; YANG, C.; Voltammetric determination of bisphenol a using an acetylene black-dihexadecyl hydrogen phosphate composite film-modified electrode. Analytical Letters, v. 40, n. 16-18, 3280-3289, 2007.

69.KAWAGUCHI, T.; YASUDA, H.; SHIMAZU, K.; PORTER, M. D.; Electrochemical quartz crystal microbalance investigation of the reductive desorption of self-assembled monolayers of alkanethiols and mercaptoalkanoic acids on Au. Langmuir, v. 16, n. 25, 98309840, 2000.

70.VERICAT, C.; VELA, M. E.; BENITEZ, G.; CARRO, P.; SALVAREZZA, R. C.; Selfassembled monolayers of thiols and dithiols on gold: new challenges for a well-known system. Chemical Society Reviews, v. 39, n. 5, 1805-1834, 2010.

71.QIU, Y.; FAN, H.; LIU, X.; AI, S.; TANG, T.; HAN, R.; Electrochemical detection of DNA damage induced by in situ generated bisphenol A radicals through electro-oxidation. Microchimica Acta, v. 171, n. 3-4, 363-369, 2010.

72.Analytical Methods Committee. Analyst 112 v. 199, n., 1987.

73.NIU, X.; YANG, W.; WANG, G.; REN, J.; GUO, H.; GAO, J.; A novel electrochemical sensor of bisphenol A based on stacked graphene nanofibers/gold nanoparticles composite modified glassy carbon electrode. Electrochim. Acta, v. 98, n. 0, 167-175, 2013. 
74.GAO, Y.; CAO, Y.; YANG, D.; LUO, X.; TANG, Y.; LI, H.; Sensitivity and selectivity determination of bisphenol A using SWCNT-CD conjugate modified glassy carbon electrode. J. Hazard. Mater., v. 199-200, n. 0, 111-118, 2012.

75.YIN, H.-S.; ZHOU, Y.-L.; AI, S.-Y.; Preparation and characteristic of cobalt phthalocyanine modified carbon paste electrode for bisphenol A detection. J. Electroanal. Chem., v. 626, n. 1-2, 80-88, 2009. 